\title{
Construção de Imagens \\ Panorâmicas \\ a partir de Vídeo
}

Henrique Pedreira de Freitas Ceribelli

\author{
Dissertação apresentada \\ ao \\ Instituto de Matemática e Estatística \\ da \\ Universidade de São Paulo \\ para \\ obtenção do grau \\ de \\ Mestre em Ciência da Computação
}

Área de Concentração: Processamento de Imagens

Orientador: Prof. Dr. Carlos Hitoshi Morimoto

São Paulo, Maio de 2004 


\title{
Construção de Imagens Panorâmicas a partir de Vídeo
}

\author{
Este exemplar corresponde à redação final \\ da dissertação devidamente corrigida e defendida \\ por Henrique Pedreira de Freitas Ceribelli \\ e aprovada pela comissão julgadora.
}

São Paulo, 18 de agosto de 2004

Banca Examinadora:

Prof. Dr. Carlos Hitoshi Morimoto (orientador, IME/USP)

Prof. Dr. Ronaldo Fumio Hashimoto (IME/USP)

Profa. Dra. Anna Helena Reali Costa (PCS / EPUSP) 
"O mais importante e bonito, do mundo, é isto: que as pessoas não estão sempre iguais, ainda não foram terminadas - mas que elas vão sempre mudando..." João Guimarães Rosa 
Ao meu orientador, Professor Doutor Carlos Hitoshi Morimoto, pela sugestão do tema e pela inestimável ajuda durante a elaboração desta dissertação.

À minha família, por sempre estar à disposição quando precisei de apoio e por acreditar no sucesso da realização deste trabalho.

Aos meus amigos, que compreenderam minha dedicação e abdicaram de minha atenção em prol do desenvolvimento deste projeto.

Ao amigo Gustavo de Almeida Varo, pela valiosíssima ajuda na programação do sistema desenvolvido, em especial nas dúvidas sobre GDI+ e DirectX.

Aos meus chefes, Ricardo Mandacaru Guerra e Katia Rossetti Mata, que me dispensaram do trabalho nos horários das aulas e das reuniões com meu orientador.

Ao meu orientador inicial, professor doutor Antonio Elias Fabris, pelo incentivo para a realização do mestrado e pelo enorme conhecimento compartilhado.

A todos os pesquisadores que escreveram os ótimos artigos que foram lidos durante a elaboração da dissertação, e cuja pesquisa contribui para o avanço tecnológico. 
A geração de imagens panorâmicas a partir de fotografias e, mais recentemente, de imagens de vídeo tem sido muito utilizada, a fim de reduzir a limitação do campo de visão da câmera, facilitando a visualização de áreas muito vastas.

Essa dissertação descreve o processo de geração de imagens panorâmicas, ou mosaicos, a partir uma seqüência de vídeo. Para isso foram revisados os principais conceitos envolvidos na criação dessas imagens. A construção de mosaicos envolve três etapas: a primeira é a estimação de movimentos, para determinar a transformação que permite o alinhamento entre duas imagens, seguido do alinhamento em si, que transforma uma das imagens para construir o mosaico, e por último a integração das imagens, necessária para minimizar as diferenças visuais, principalmente nas bordas.

Utilizando um micro computador PC Pentium IV $2.6 \mathrm{GHz}$, foi desenvolvido um sistema para construção de mosaicos em tempo real, capaz de processar 10 imagens por segundo, provindas de uma câmera colorida na resolução de $320 \times 240$ pixels. O sistema permite ainda outros formatos de entrada, como AVI, MPEG, JPEG etc. Para melhorar a qualidade da imagem panorâmica final, foram desenvolvidas também técnicas capazes de compensar mudanças de iluminação entre imagens e minimizar erros de alinhamento devido a distorções da lente da câmera. 
The need to combine pictures into panoramic mosaics exists since the beginning of photography, as the camera's field of view is always smaller than the human field of view. While scissors and glue are the tools used in film photography, more sophisticated methods were enabled with digital video.

Three major issues are important in image mosaicking: motion estimation (determines the transformation that aligns the images), image alignment (warp each frame of the input video or image sequence to a common surface) and image blending (necessary to overcome the intensity difference or misalignment between images.

A real time solution was developed on a workstation with a Pentium IV $2.6 \mathrm{GHz}$. The system is able to process 10 frames per second, using color images of resolution $320 \times 240$ pixels. The system also allows different input formats, such as MPEG, AVI, JPEG, etc. To enhance the quality of the output mosaic image, the system compensates for intensity differences between images and minimizes misalignment due to lens distortions. 



\section{Sumário}

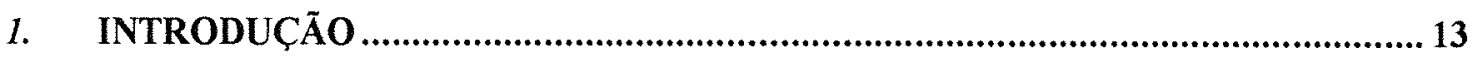

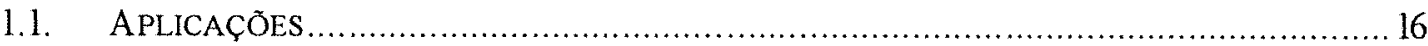

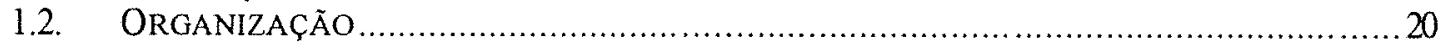

2. O PROBLEMA DE ESTIMAÇÃO DE MOVIMENTO........................................... 21

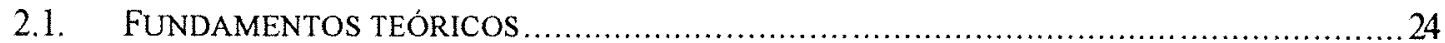

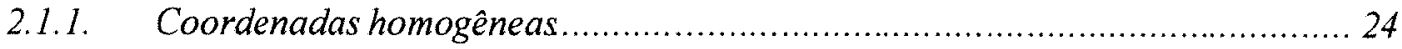

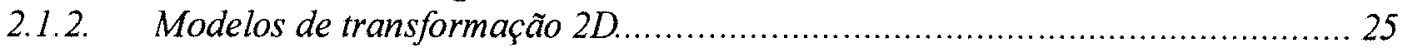

2.1.3. Modelos de transformação perspectiva .................................................... 28

2.2. ESTIMAÇÃO DO MOVIMENT O - TRABALHOS CORRELATOS........................................30

2.2.1. Estimação do movimento para cenas $2 D$........................................................ 31

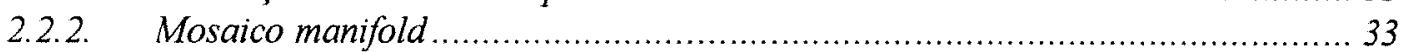

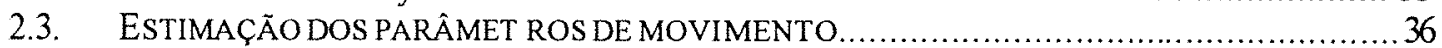

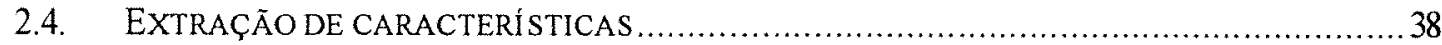

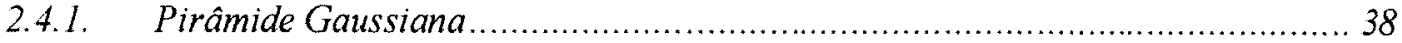

2.4.1.1. Interpolação da pirâmide Gaussiana ....................................................... 40

2.4.2. Pirâmide Laplaciana ............................................................................ 40

2.4.3. Seleção das características a partir da Laplaciana ........................................ 44

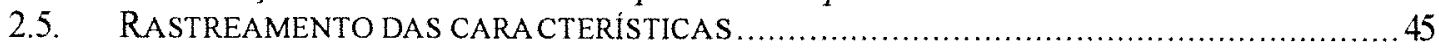

3. ALINHAMENTO E INTEGRAÇÃO DE IMAGENS...............................................47

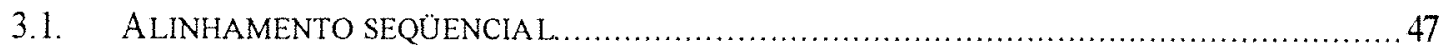

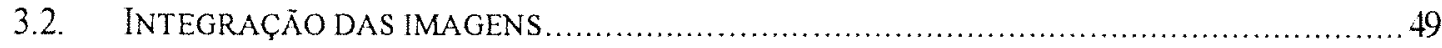

4. DESCRIÇÃO DA SOLUÇÃO DESENVOLVIDA...............................................53

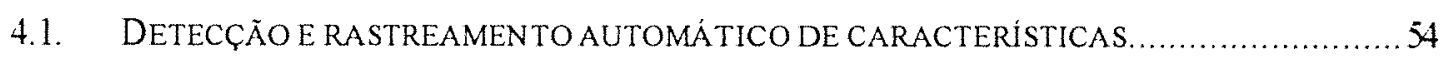

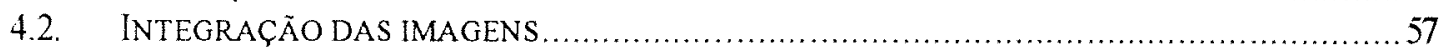

4.2.1. Simplificação do diagrama de Voronoi ........................................................ 58

4.2.2. Média com peso proporcional da distância ............................................... 59

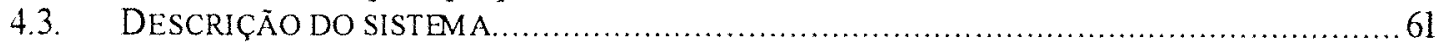




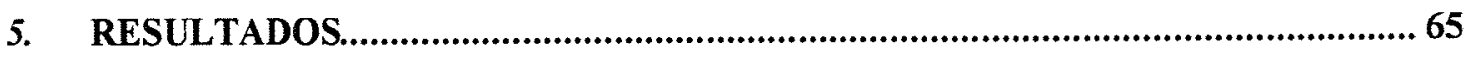

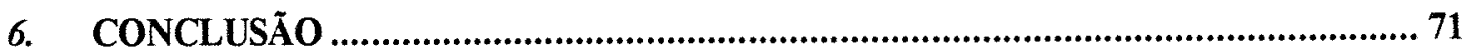

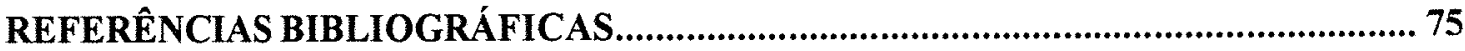




\section{Lista de Figuras}

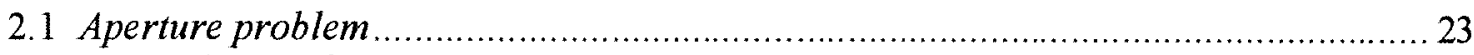

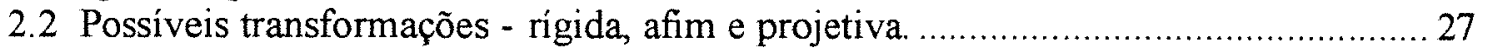

2.3 Sistema de coordenadas cartesianas fixo na câmera............................................... 27

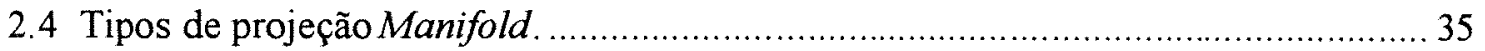

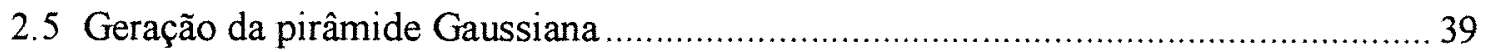

2.6 Processo de construção da imagem Laplacian.................................................... 41

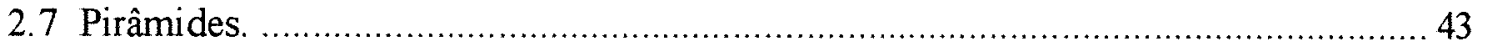

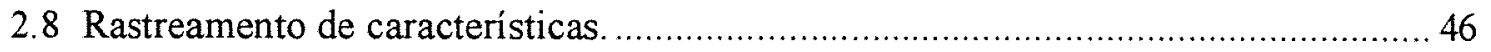

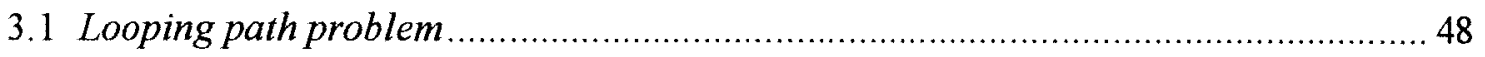

4.1 Pirâmides de 2 níveis utilizadas na detecção de características ................................ 55

4.2 Mosaico de 6 imagens da vista da Vila Olímpia. ................................................ 61

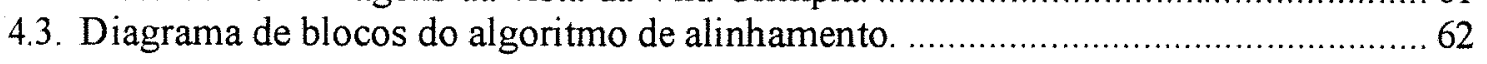

5.1 Mosaico de 29 imagens da vista da Vila Olimpia. ..................................................6 66

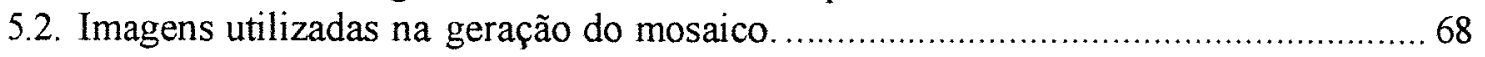

5.3. Mosaico gerado a partir uma seqüência de 16 imagens obtidas de um vídeo. .........6 68

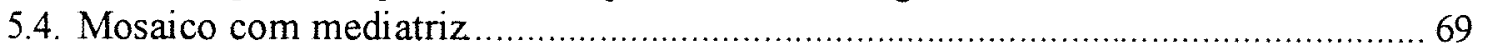




\section{Lista de Tabelas}

4.1 Matriz utilizada no filtro Gaussiano.

5.1 Comparação do tempo de processamento ao aumentar a janela de busca................. 70

5.2 Comparação do tempo de processamento ao aumentar número de partições.

70 


\section{Introdução}

A necessidade de se combinar fotos em uma imagem panorâmica existe desde o início da fotografia, pois o campo de visão da câmera é, em geral, menor do que o campo visual humano. Enquanto tesoura e cola são as ferramentas utilizadas para compor fotos tradicionais, existem métodos mais sofisticados quando se trabalha com fotos digitais.

Apesar de existirem câmeras com dispositivos especiais capazes de tirar fotos mais amplas que o padrão (como câmeras onidirecionais [38][31]), ainda se está limitado às amplitudes máximas e distorções destas. Além disso, quando se tira uma foto com uma câmera assim, mapeia-se uma cena inteira na resolução limitada desta, ou seja, o nível de detalhamento da foto estará limitado à resolução máxima da câmera. Por outro lado, no vídeo digital é possivel alinhar e colar a seqüência de imagens indefinidamente, criando assim uma vista panorâmica da cena.

Esse processo de alinhamento automático de múltiplas imagens em um conjunto mais amplo é chamado de gração de imagens panorâmicas, ou ainda de geração de mosaicos (mosaicking) [48]. "Mosaico é uma representação comum para conjunto de elementos justapostos ou conglomerados, ou seja, uma representação fotográfica contínua de uma área, montada a partir de conjunto de fotografias reunidas" [30]. Assim, no decorrer 
dessa dissertação, mosaico será utilizado como sinônimo de imagem panorâmica (resultante do alinhamento de uma seqüência de imagens).

$\mathrm{Na}$ interação com sistemas virtuais, a construção de imagens panorâmicas permite que se tenha uma visão mais ampla e realista da cena com que se vai interagir.

Um exemplo seria girar uma câmera de vídeo ao redor do seu próprio eixo (utilizando um tripé, por exemplo), para capturar uma visão de 360 graus da cena. Neste caso, o alinhamento e a posterior composição dessa seqüência de imagens gera uma imagem panorâmica que representa a projeção da cena em um cilindro [47].

Além disso, é possível obter uma visão panorâmica da superficie da Terra unindo fotos tiradas de satélites ou montar imagens detalhadas de galáxias e nebulosas a partir de múltiplas imagens de telescópios [5]. Nestes casos, gera-se o mosaico para se obter uma imagem com um campo de visão ou um nível de detalhe muito maior do que poderia ser obtido através de uma única fotografia.

Mosaicos gerados a partir de seqüências de imagens do solo oceânico são utilizados por cientistas para compreender melhor a biologia e geologia do oceano, além de serem utilizados para ajudar a visualizar destroços de navios naufragados [26]. Os mosaicos ajudam a se obter uma visão macro no terreno subaquático, dado que o campo visual é muito limitado debaixo d'água devido à atenuação da luz conforme a profundidade do solo oceânico aumenta.

Para construir imagens panorâmicas, a partir de uma seqüência de imagens, é preciso estimar o movimento realizado pela câmera (utilizando algum modelo de transformação), combinar as imagens sobrepostas e, por último, corrigir as distorções e diferenças de intensidade entre as imagens.

As pesquisas sobre geração de mosaicos foram iniciadas há muitos anos com a fotogrametria, em que a união de fotografias aéreas era utilizada na medição de áreas e edição de mapas e gráficos [52]. Entretanto, com o desenvolvimento de diversas técnicas mais eficientes de alinhamento de imagens, tornourse realidade a criação de mosaicos a partir de seqüências de vídeo, abrindo um leque de aplicações tanto na área gráfica quanto nas áreas de compressão, edição, navegação e indexação de vídeo [18][17], além de aplicações em robótica [49][3]. 
Existem alguns recursos extras, como lentes especiais, que podem se conectar a câmera a fim de se aprimorar o processo de geração de mosaicos. Pode-se, por exemplo, conectar a câmera um filtro óptico com um domínio espacialmente variado, de modo que ao se mover a câmera, cada ponto da cena é sensibilizado por diferentes regiões do filtro. Assim, múltiplas medidas são obtidas para cada ponto da cena sob diferentes configurações ópticas. Unindo as informações capturadas em múltiplas imagens produzem-se mosaicos que possuem informações adicionais sobre a cena, sendo possível, por exemplo, aumentar a resolução do mosaico gerado. Esta abordagem é conhecida como Generalized Mosaicking [43].

O problema principal abordado nesta dissertação é a construção de imagens panorâmicas e os principais passos norteadores para a sua resolução. Assim, é necessário compreender os passos básicos envolvidos no processo de geração de mosaicos [36], que são:

- Estimação de movimentos: determinar a transformação que alinha duas imagens sucessivas, ou uma imagem com o mosaico atual. Em alguns casos, simples operações de translação e rotação descrevem corretamente a transformação; em outros, é necessário utilizar uma transformação mais complexa, como a transformação projetiva.

- Cortar e colar a imagem (alinhamento de imagens): grande parte das regiões em um mosaico panorâmico são sobrepostas ou cobertas por mais de uma imagem. Este processo envolve tanto a seleção de uma imagem simples para cada região sobreposta quanto algum tipo de combinação de todas as imagens sobrepostas.

- Integração das imagens (construção do mosaico): necessária para superar as diferenças de intensidade entre as imagens, com o propósito de melhorar a qualidade visual do mosaico ao longo das "costuras" (bordas da imagem alinhada). Essas diferenças ocorrem mesmo quando as imagens são perfeitamente 
alinhadas, devido a diversos fatores, como, por exemplo, diferenças na intensidade luminosa, distorções na image $\mathrm{m}$, objetos em movimento, entre outros.

\subsection{Aplicações}

A geração de mosaicos a partir de fotografias e, mais recentemente, de imagens de vídeo tem sido muito utilizada, a fim de reduzir a limitação do campo de visão da câmera, facilitando a visualização de áreas muito vastas.

Mas as aplicações de mosaicos não se restringem a isso. O processo de estimação de movimento da câmera, que é usado na criação de mosaicos, pode ser utilizado para outras aplicações, como será descrito a seguir. Além disso, dependendo do método de integração utilizado na geração de um mosaico, obtém-se diferentes tipos de mosaicos que podem ter diversas finalidades. Assim, algumas das aplicações possíveis são:

- Segmentação da cena: o movimento realizado pela câmera em relação a um objeto estático em uma cena é diferente do movimento realizado pela câmera em relação a um objeto em movimento, ou em relação a um objeto bem mais próximo da câmera do que outros mais distantes. Dessa forma, as divergências nos valores dos parâmetros estimados para uma determinada região ajudam na segmentação da imagem em regiões que correspondem a diferentes objetos, tornando possível segmentar cada região em camadas, como descrito por Wang e Adelson em [50] e por Odone, Fusiello e Trucco em [32]. Após a segmentação da cena em camadas, é possível remover as camadas que correspondem a objetos em movimento, obtendo-se uma imagem "limpa" do plano de fundo dominante da cena. Além disso, é possível realizar outras edições no vídeo, como inserção de imagens nesse plano de fundo e posterior inserção dos objetos em movimento que foram removidos, obtendo-se a sequência de vídeo original, com uma nova imagem na cena (como por exemplo, uma placa de propaganda) [33]. 
- Compressão de vídeo: uma seqüência de vídeo geralmente contém diversas imagens de uma mesma cena, as quais são obtidas por diferentes ângulos de visão, ou seja, sucessivas imagens de vídeo geralmente se sobrepõem em grande parte. Devido a essa sobreposição, um mosaico fornece uma redução muito significativa do total de dados necessários para se representar uma cena. Assim, é possível eliminar essas redundâncias existentes nos quadros (devido aos diferentes pontos de vista), obtendo-se uma representação compacta do vídeo [18]. O padrão MPEG-4 [22] utiliza uma representação em camadas das informações de vídeo. A cena é considerada como sendo composta por diversos objetos de vídeo (Vídeo Objects - VOs). Cada VO é caracterizado por uma propriedade intrínseca, como forma, textura ou movimento. Neste contexto, "objeto" tem uma interpretação muito generalizada, e não é necessariamente um objeto físico. Por exemplo, a região do plano de fundo da cena (background) pode ser considerada como um VO. Um sprite consiste em uma destas regiões de um VO que está presente na cena durante todo um segmento de vídeo. Um exemplo de um sprite é um mosaico gerado por imagens do plano de fundo de uma seqüência de vídeo em que a câmera está tomando uma panorâmica (panning). $O$ padrão MPEG-4 não prescreve o método para se criar VOs, mas simplesmente fornece uma convenção padrão para descrevê-los, de forma que todos os decodificadores complacentes sejam capazes de extrair os VOs a partir do fluxo de bits codificados. Desse modo, um grande mosaico panorâmico do plano de fundo da cena (um sprite, na terminologia do MPEG-4) é transmitido para o receptor apenas uma vez. $O$ restante dos objetos em movimento existentes na cena são transmitidos separadamente como VOs, além de todas as transformações existentes, a fim de se construir a seqüência original.

- Indexação e navegação de vídeo: a representação seqüencial e redundante baseada em quadros de um vídeo na qual a informação da cena é distribuída através de vários quadros é transformada em uma representação compacta e explícita, em que cada quadro pode ser diretamente relacionado a partir do mosaico construído [17]. Essa representação compacta de dados de vídeo permite 
uma navegação não linear e uma efíciente indexação que fornece um rápido acesso à informação de interesse.

- Passeio virtual: em um sistema virtual, como um passeio através de uma construção histórica (um palácio ou um museu), deseja-se ter uma visão completa da cena, isto é, mosaicos que cobrem todo o campo de visão e, portanto, permitem que o usuário possa olhar em todas as direções [48][46]. Em um outro exemplo, um passeio virtual por sua casa, construído a partir de mosaicos gerados de uma seqüência de imagens obtidas por uma caminhada com uma câmera de vídeo pelos ambientes da casa, poderia ser útil para vendê-la.

- Navegação automática: a estimação da posição de um veículo baseada em mosaicos é uma técnica que utiliza imagens (em tempo real) para rastrear o movimento sobre uma imagem de alta resolução, previamente armazenada, de uma área conhecida. Dessa maneira, um veículo equipado com uma câmera direcionada para o chão pode rastrear seu movimento combinando as imagens da câmera com uma imagem ampla do chão (mapa) [49] [42]. A principal vantagem desta técnica é o baixo custo, pois essa solução é livre de uma infra-estrutura para guiar o veículo automaticamente, como trilhos. Assim, essa solução pode ser utilizada em ambientes que tenham superficies planas e com textura, como o chão de uma fábrica, por exemplo. Além disso, essa técnica também é muito utilizada para navegação automática de veículos subaquáticos (Autonomous Underwater Vehicle - AUV), em que mosaicos gerados a partir de imagens do solo oceânico são usados como mapas [11][9].

- Análise automática de um jogo de futebol: uma visão panorâmica do campo de futebol é gerada a partir de uma seqüência de imagens desse jogo, e os objetos em movimento (jogadores e bola) são detectados e rastreados. Faz-se então uma transformação perspectiva na imagem panorâmica gerada, obtendo-se uma visão superior do campo, e realiza-se uma análise da movimentação dos jogadores em campo, das jogadas de gol etc. Entretanto, só é possível estimar os parâmetros de 
movimento (para gerar a visão panorâmica) em regiões com textura, como as linhas do campo (grande área, círculo central etc), traves do gol e placas de propaganda [53][54][44]. Além disso, existem métodos para análise de outros esportes, como futebol americano, por exemplo, no qual as linhas de marcação das jardas auxiliam na estimação dos parâmetros de movimento [15].

- Aumento na resolução de uma imagem: a resolução de uma imagem depende das características físicas do sensor que a capturou. Assim, para se obter uma imagem com uma resolução maior, a troca desse sensor pode não ser uma opção plausível. Nesse caso, pode-se aumentar a resolução de uma imagem por meio do alinhamento de diversas amostras da cena em diferentes posições [19][24][58].

- Extração de informações sobre estruturas 3D: em uma sequência de imagens de uma cena que contém objetos em diferentes profundidades e com textura suficiente para dar a noção de profundidade (regiões com intensidade uniforme não dão), é possivel aplicar a técnica de geração de mosaicos para as regiões planas de cada imagem, segmentando as imagens em diversos componentes planos. Uma vez que cada região plana independente foi identificada, é possível deduzir o componente $z$ associado a cada pixel da seqüência de imagens dada, a fim de restaurar informações sobre a profundidade da cena [48].

- Estabilização de imagens: é o processo de remoção do movimento indesejado de uma seqüência de vídeo por meio do alinhamento de cada imagem da seqüência com a primeira image m desta. Para se obter uma visualização mais natural de, por exemplo, uma seqüência de vídeo proveniente de uma câmera em um carro em movimento, pode-se filtrar as oscilações existentes devido às irregularidades no terreno, obtendo um movimento mais suave, como se o veículo estivesse andando sobre um terreno liso, como descrito por Morimoto e Chellappa em [29] [28]. 


\subsection{Organização}

Este trabalho é dividido da seguinte maneira: o capítulo 2 revisa os principais conceitos e problemas encontrados no processo de estimação dos movimentos (primeiro passo na geração de mosaicos), enquanto o capítulo 3 apresenta os passos restantes necessários para se gerar mosaicos - alinhamento e integração das imagens. $O$ capítulo 4 descreve o sistema que foi implementado para geração de imagens panorâmicas a partir de vídeo. O capítulo 5 inclui uma descrição detalhada dos resultados obtidos, e, finalmente, o capítulo 6 encerra a dissertação com as conclusões do trabalho. 
CAPITULO

2.

\section{O Problema de Estimação de Movimento}

Este capítulo define o problema da estimação de movimento e apresenta algumas das soluções mais comuns encontradas na literatura. Apresenta também os fundamentos principais do processo de construção de imagens panorâmicas.

O problema de estimar o movimento da câmera consiste em obter os parâmetros da transformação que mapeiam o movimento realizado pela câmera a partir de pontos correspondentes da imagem. Assim, informações obtidas por dife rentes fontes podem ser combinadas e as mudanças ocorridas na cena, no decorrer do tempo em que as imagens foram obtidas, podem ser determinadas.

Entretanto, dependendo da complexidade do movimento da câmera e da estrutura da cena, existem alguns fatores que dificultam o alinhamento das imagens, como objetos em movimento, distorções causadas pela lente da câmera ou paralaxe 3D. É preciso, por exemplo, levar em consideração que o movimento realizado pela câmera em relação a um objeto estático em uma cena é diferente do movimento realizado pela câmera em relação a um objeto em movimento, ou em relação a um objeto bem mais próximo da câmera do que outros mais distantes. Dessa forma, existem diversos movimentos a serem estimados na cena e divergências nos valores dos parâmetros estimados para uma determinada 
região podem ajudar na segmentação da imagem em regiões que correspondem a diferentes objetos.

Quando a cena não possui objetos em movimento e é predominantemente plana, ou seja, a cena pode ser considerada com sendo um objeto rígido (estático), a estimação de movimento se resume à estimação do movimento realizado pela câmera. No sistema desenvolvido nesse trabalho, considera-se que a cena possui estas características, de modo que a estimação de movimento é referenciada como sendo estimação do movimento realizado pela câmera em relação a uma cena estática.

Para se estimar o movimento, existem diferentes métodos que podem ser divididos em duas categorias principais:

- Métodos diretos: utilizam informações de todos os pixels para estimar o movimento [16][13]. Atualizam iterativamente os parâmetros da transformação de alinhamento, de modo que uma função particular de custo é minimizada. Utiliza-se fluxo óptico (optical flow) ou correlação de fases para estimar os parâmetros da transformação. Fluxo óptico é a distribuição das velocidades aparentes do movimento do modelo de intensidade luminosa (brightness patterns) da imagem. O fluxo óptico pode surgir do movimento relativo entre os objetos e o observador (câmera). Conseqüentemente, o fluxo óptico pode fornecer informações importantes sobre o arranjo espacial dos objetos visualizados e a proporção de mudanças nesse arranjo. Descontinuidades no fluxo óptico podem ajudar na segmentação da imagem em regiões que correspondem a diferentes objetos. Entretanto, a relação entre o fluxo óptico no plano da imagem e a velocidade dos objetos no mundo tridimensional não é necessariamente óbvia, pois um objeto em movimento pode produzir uma imagem de intensidade luminosa constante. Considere, por exemplo, uma esfera uniforme que exibe sombreamento, pois os elementos da sua superficie são orientados em muitas direções diferentes. Quando essa esfera está girando, apesar de existir um movimento, o fluxo óptico é zero em todos os pontos da imagem, pois o sombreamento da iluminação é constante sobre a superficie da esfera. Assim, nem sempre o fluxo óptico é capaz de representar o movimento do pixel. Além disso, esse método é muito afetado por um problema clássico da estimação de movimento chamado aperture problem [27]. Tal problema 
ocorre quando a representação da imagem não possui textura suficiente para que seja possivel extrair o movimento do ponto, ou seja, é uma conseqüência da ambigüidade de um movimento de 1-dimensão de um padrão simples, visto através de um buraco (visão limitada). Dado um plano listrado sendo observado através de um buraco, como representado na Figura 2.1.a, se o plano for movido para baixo, o padrão de linhas dentro do buraco altera-se (Figura 2.1.b). Mas se o plano listrado for movido para esquerda, o padrão de linhas dentro do buraco altera-se da mesma maneira (Figura 2.1.c). Assim, a percepção sobre a direção do movimento é ambígua e só é possivel estimar-se o fluxo normal ao movimento (normal flow).

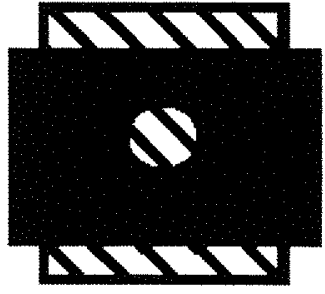

a)

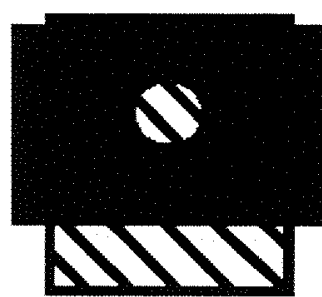

b)

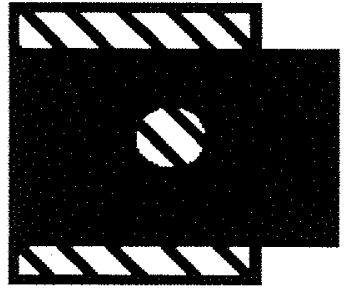

c)

Figura 2.1 : aperture problem - o deslocamento do plano listrado para baixo ou para a esquerda faz com que o padrão observado dentro do buraco mova -se da mesma maneira, tornando impossivel estimar a direção do deslocamento corretamente.

a) Plano com listras observado por um buraco;

b) Plano com listras deslocourse 14 pixels para baixo;

c) Plano com listras deslocourse 15 pixels para a esquerda em relação ao item (a).

- Métodos baseados em características da imagem (feature-based): identificam algumas características comuns entre pares de imagens, como cantos (regiões com grande diferença na intensidade luminosa dos pixels), linhas etc, e o movimento da câmera é estimado utilizando somente os pontos de correspondência selecionados [45][7][56]. Dessa forma, estima-se o movimento da maioria das características da cena, ou seja, do movimento dominante da cena, que é, geralmente, o movimento da câmera em relação ao plano dominante da cena. Assim, esses métodos necessitam ser capazes de identificar boas caracteristicas, conforme descrito na seção 2.5. Tais métodos são mais utilizados em implementações que visam gerar mosaicos em tempo 
real, pois como não trabalham com todos os pontos da imagem, possuem um custo computacional mais baixo do que os métodos diretos.

\subsection{Fundamentos teóricos}

Para relacionar cada imagem a uma representação comum (mosaico) é necessário determinar a transformação capaz de alinhar cada quadro da seqüência de imagens com o mosaico. Mas, antes de se determinar a transformação necessária para se alinhar duas imagens, é preciso conhecer algumas propriedades básicas de transformação de imagens.

\subsubsection{Coordenadas homogêneas}

Usando a notação vetorial, um ponto 3D qualquer $P=(x, y, z)^{t}$ no sistema de coordenadas cartesianas é transformado por translação, escala e rotação conforme:

$$
\begin{aligned}
& P^{\prime}=P+D \\
& P^{\prime}=P S \\
& P^{\prime}=P R
\end{aligned}
$$

onde $D$ é o vetor de translação, $S$ e $R$ são as matrizes de escala e $P$ ' é o ponto $P$ após sofrer a respectiva transformação.

Essas três operações (e suas combinações) são as transformações mais utilizadas em computação gráfica e, para tornar possivel tratar tais operações do mesmo modo e de forma combinada, utilizam-se coordenadas homogêneas [51]. Efetivamente, aumenta-se a dimensionalidade do espaço para tornar a translação uma transformação linear. $\mathrm{Na}$ prática, isso proporciona um sistema unificado para a especificação das transformações. 
Utilizando coorderadas homogêneas, um ponto

$$
P=(x, y, z)^{\mathbf{t}}
$$

do sistema de coordenadas cartesianas é representado como

$$
P=(X, Y, Z, w)^{\mathrm{t}}
$$

para qualquer fator de escala $w$ ? 0 . A representação tridimensional das coordenadas cartesianas é dada por:

$$
\begin{aligned}
& x=X / w \\
& y=Y / w \\
& z=Z w
\end{aligned}
$$

Em outras palavras, pontos $3 \mathrm{D}$ com coordenadas homogêneas $(\mathrm{X}, \mathrm{Y}, \mathrm{Z}, \mathrm{w})^{\mathrm{t}}$ possuem coordenadas cartesianas $(\mathrm{X} / \mathrm{w}, \mathrm{Y} / \mathrm{w}, \mathrm{Z} / \mathrm{w})^{\mathrm{t}}$.

Da mesma forma, denotam-se pontos $2 \mathrm{D}$ em uma imagem plana como sendo $(x, y$, $w) t$, sendo $(x / w, y / w) t$ as coordenadas cartesianas correspondentes.

No espaço afim, $w$ é igual a 1 e, assim, a representação vetorial de um ponto 3D utilizando coordenadas homogêneas é $(X, Y, Z, 1)^{t}$.

\subsubsection{Modelos de transformação 2D}

Dadas duas imagens (uma imagem de referência e uma de inspeção), a classe de transformações afins 2D pode ser representada, utilizando coordenadas homogêneas, por:

$$
\left[\begin{array}{c}
x^{\prime} \\
y^{\prime} \\
w^{\prime}
\end{array}\right]=\left[\begin{array}{lll}
m_{0} & m_{1} & m_{2} \\
m_{3} & m_{4} & m_{5} \\
m_{6} & m_{7} & m_{8}
\end{array}\right]\left[\begin{array}{l}
x \\
y \\
w
\end{array}\right] \text { ou } p^{\prime}=M_{2 D} p
$$


onde $(x, y, w)^{t}$ representa as coordenadas homogêneas de um ponto $p$ da imagem de referência, e $\left(x^{\prime}, y^{\prime}, w\right)^{t}$ são as coordenadas homogêneas do ponto $p^{\prime}$ correspondente (na imagem de inspeção). Os valores dos parâmetros $m_{3}, \ldots, m_{8}$ da matriz $\mathrm{M}_{2}$ definem as possíveis transformações planas (modelos de transformação 2D) existentes e são chamados de parâmetros de movimento [48].

As transformações mais simples são translações, seguidas por translações com rotações (transformações rígidas), mais mudança de escala (transformações de similaridade), transformações afins e transformações projetivas.

Transformações rígidas, nas quais são permitidas translações e as rotações são restritas somente ao redor do eixo óptico, têm a seguinte forma da matriz $\mathrm{M}_{2 \mathrm{D}}$,

$$
\mathrm{M}_{\text {rigida }-2 \mathrm{D}}=\left[\begin{array}{ccc}
\cos \theta & -\operatorname{sen} \theta & t_{x} \\
\operatorname{sen} \theta & \cos \theta & t_{y} \\
0 & 0 & 1
\end{array}\right]
$$

onde o parâmetro? define a rotação ao redor do eixo óptico, $t_{x}$ a translação no eixo $x$ e $t_{y}$ a translação no eixo y. O conjunto de todas essas transformações de 3 parâmetros formam o grupo Euclidiano [2].

As transformações defínidas por quatro parâmetros (além dos 3 parâmetros do grupo Euclidiano, inclui-se também um fator de escala) preservam os ângulos e os comprimentos relativos e pertencem ao grupo de similaridades.

As transformações do grupo afim são definidas por 6-parâmetros (incluem os parâmetros de cisalhamento), que são obtidas relaxando a restrição de rotação ao redor do eixo óptico. Sua matriz de transformação tem a seguinte forma:

$$
\mathrm{M}_{\text {afim-2D }}=\left[\begin{array}{ccc}
m_{0} & m_{1} & m_{2} \\
m_{3} & m_{4} & m_{5} \\
0 & 0 & 1
\end{array}\right] .
$$

Os ângulos e os comprimentos não são mais preservados nessa transformação, embora linhas paralelas continuem paralelas. 
Enquanto isso, uma transformação projetiva tem uma matriz $\mathrm{M}_{\mathrm{D}}$ geral com 8 graus de liberdade. Note que duas matrizes M são equivalentes se elas são múltiplos escalares uma da outra. Dessa forma, como não é possível estimar o nono parâmetro, atribui-se a esse o valor 1 , ou seja, $m_{8}=1$.

A Figura 2.2 mostra um quadrado e exemplos de possíveis transformações - rígida, afim e projetiva - da esquerda para direita.
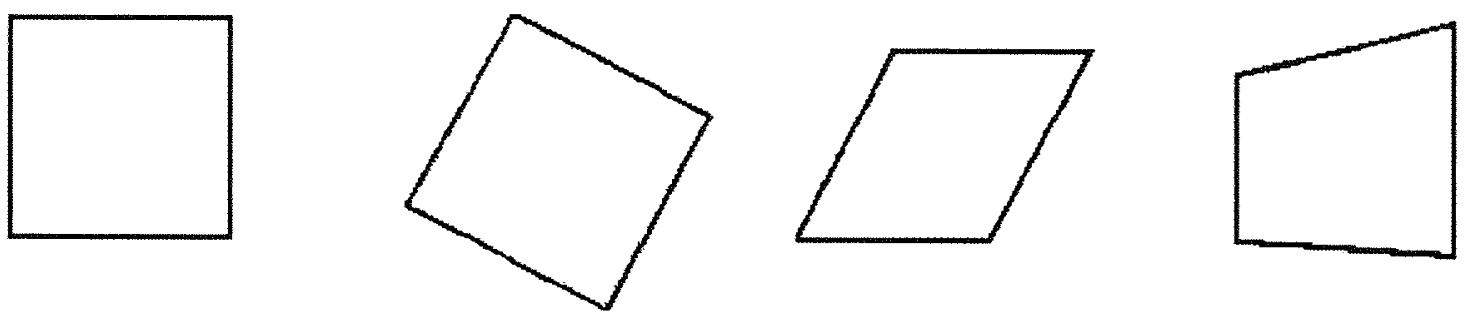

Figura 2.2: um quadrado e exemplos de possiveis transformações - rígida, afim e projetiva - da esquerda para direita.

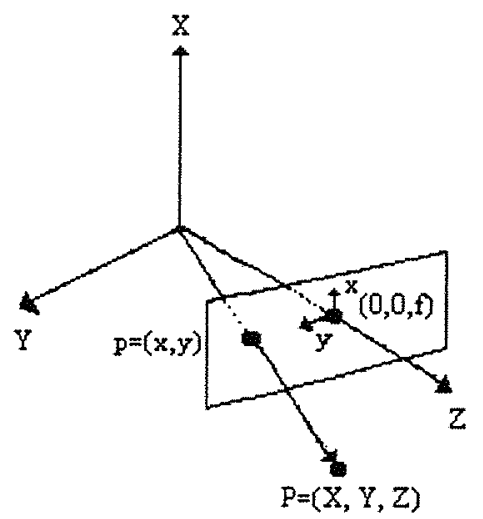

Figura 2.3: sistema de coordenada s cartesianas fixo na câmera. 


\subsubsection{Modelos de transformação perspectiva}

Suponha que a câmera esteja localizada na origem do sistema de coordenadas definido pelos eixos $X, Y$ e $Z$, e sejam $P=(X, Y, Z)^{\dagger}$ e $p=(x, y)^{t}$, um ponto qualquer no sistema de coordenadas cartesianas e a projeção de $P$ correspondente no plano da imagem, respectivamente (ver Figura 2.3). O plano definido pelos eixos $x$ e $y$ é perpendicular ao eixo $Z$ e corta esse eixo no ponto $f$, em que $f$ é a distância entre o centro da lente da câmera e o plano de projeção (foco), ou seja, $f$ é o comprimento focal da câmera.

Assim, a projeção perspectiva do ponto $P$ no plano da imagem (ponto $p$ ) é dada por:

$$
p=\left(\begin{array}{l}
x \\
y
\end{array}\right)=\left(\begin{array}{c}
f \frac{X}{Z} \\
f \frac{Y}{Z}
\end{array}\right), \text { onde } f \text { é o comprimento focal da câmera }
$$

Assumindo uma transformação $3 \mathrm{D}$ rígida, um movimento arbitrário da câmera pode ser descrito por uma translação $T$ e uma rotação $R$, de modo que um ponto $P_{0}$ no sistema de coordenadas da câmera em um tempo $t_{0}$ é descrito em uma nova posição da câmera em $t_{1}$ por:

$$
\mathrm{P}_{1}=\mathrm{RP}_{0}+\mathrm{T} \rightarrow\left(\begin{array}{l}
X_{1} \\
Y_{1} \\
Z_{1}
\end{array}\right) \cdot\left(\begin{array}{lll}
r_{11} & r_{12} & r_{13} \\
r_{21} & r_{22} & r_{23} \\
r_{31} & r_{32} & r_{33}
\end{array}\right)\left(\begin{array}{l}
X_{0} \\
Y_{0} \\
Z_{0}
\end{array}\right)+\left(\begin{array}{l}
T_{X} \\
T_{Y} \\
T_{Z}
\end{array}\right)
$$

onde $R$ é uma matriz ortonormal $3 \times 3$.

A projeção perspectiva do ponto $P_{1}$ no plano da imagem (ponto $p_{1}$ ) pode ser obtida combinando (2.2) com (2.3):

$$
\mathrm{p}_{1}=\left(\begin{array}{c}
f \frac{X_{1}}{Z_{1}} \\
f \frac{Y_{1}}{Z_{1}}
\end{array}\right)=\left(\begin{array}{l}
f \frac{\left(r_{11} x_{0}+r_{12} y_{0}+r_{13} f+f\left(T_{X} / Z_{0}\right)\right)}{\left(r_{31} x_{0}+r_{32} y_{0}+r_{33} f+f\left(T_{Z} / Z_{0}\right)\right)} \\
f \frac{\left(r_{21} x_{0}+r_{22} y_{0}+r_{23} f+f\left(T_{Y} / Z_{0}\right)\right)}{\left(r_{31} x_{0}+r_{32} y_{0}+r_{33} f+f\left(T_{Z} / Z_{0}\right)\right)}
\end{array}\right)
$$


Dada a matriz de rotação $R$ para transformações 3D definida na equação (2.3), é possivel simplificá-la, para se modelar apenas rotação ao redor do eixo óptico da câmera, conforme mostrado abaixo.

$$
\left(\begin{array}{lll}
r_{11} & r_{12} & r_{13} \\
r_{21} & r_{22} & r_{23} \\
r_{31} & r_{32} & r_{33}
\end{array}\right)=\left(\begin{array}{ccc}
\cos \theta & -\operatorname{sen} \theta & 0 \\
\operatorname{sen} \theta & \cos \theta & 0 \\
0 & 0 & 1
\end{array}\right)
$$

Definindo-se $s$ e $T$ como

$$
s=\frac{Z_{0}}{Z_{0}+T_{Z}}, \quad T=\left(\begin{array}{c}
\frac{f T_{X}}{Z_{0}+T_{Z}} \\
\frac{f T_{Y}}{Z_{0}+T_{Z}}
\end{array}\right)
$$

E substituindo-se (2.5) e (2.6) na equação (2.4), obtém-se:

$$
\mathrm{p}_{1}=\mathrm{s} \mathrm{R}_{\mathrm{e}} \mathrm{p}_{0}+\mathrm{T}
$$

onde $T$ é um vetor de translação de dois parâmetros $\left(x\right.$ e $\left.t_{y}\right), s$ corresponde ao fator escalar, $p_{0}$ é a projeção perspectiva do ponto $P_{0}$ e $R_{e}$ é a matriz ortogonal de rotação, definida por:

$$
\mathrm{R}_{\mathrm{e}}=\left(\begin{array}{cc}
\cos \theta & -\operatorname{sen} \theta \\
\operatorname{sen} \theta & \cos \theta
\end{array}\right)
$$

onde o parâmetro? define a rotação ao redor do eixo óptico.

Assim, uma transformação simples capaz de alinhar duas imagens obtidas a partir do mesmo ângulo de visão, mas em uma posição diferente, é definida em (2.7), em que são utilizados quatro parâmetros (grupo de similaridades)

Transformações rígidas, nas quais escala não é permitida, também são descritas por (2.7), sendo $s$ igual a 1 (grupo Euclidiano). 
Uma transformação afim de 6-parâmetros, que é obtida relaxando as restrições na matriz de rotação, é definida por:

$$
\mathrm{p}_{1}=\left(\begin{array}{ll}
r_{11} & r_{12} \\
r_{21} & r_{22}
\end{array}\right) \mathrm{p}_{0}+\left(\begin{array}{c}
t_{x} \\
t_{y}
\end{array}\right)=\mathrm{R}_{\mathrm{a}} \mathrm{p}_{0}+\mathrm{T}
$$

O uso de modelos de ordem maior (como o modelo bilinear de 8-parâmetros ou o biquadrático de 12-parâmetros) é discutido por Mann e Picard em [25]. A família de transformações descritas até agora não é capaz de modelar algumas distorções que aparecem em modelos 3D mais gerais, como os causados pelo movimento pan-tilt, conhecido como cisalhamento (chirping). Um modelo de 8-parâmetros é suficiente para modelar um movimento arbitrário de um ponto 3D sob perspectiva, mas tal modelo requer o uso de técnicas de estimação mais complexas, que podem reduzir drasticamente a performance do sistema. Assim, como este trabalho está preocupado em gerar mosaicos em tempo real, tais modelos mais complexos não são abordados.

\subsection{Estimação do movimento - trabalhos correlatos}

Existem diversos métodos descritos na literatura [3][20][12][4], para se estimar os parâmetros dos movimentos dos objetos que compõem a cena, os quais variam conforme a complexidade desta.

Irani e Peleg [18][17] propuseram um algoritmo que vai aumentando a complexidade gradualmente de $2 \mathrm{D}$ para $3 \mathrm{D}$. Inicialmente, estima-se a transformação geométrica $2 \mathrm{D}$ dominante entre os quadros e esse alinhamento inicial compensa totalmente o movimento induzido pela câmera em cenas $2 \mathrm{D}$, enquanto em cenas $3 \mathrm{D}$ compensa apenas o movimento da superficie plana dominante da cena.

A característica chave, que permite estender o alinhamento utilizando transformação $2 \mathrm{D}$ em cenas $3 \mathrm{D}$, é que o alinhamento $2 \mathrm{D}$ remove todos os efeitos de rotação, translação e escala (zoom) da câmera sem os calcular explicitamente. Esse movimento residual de 
paralaxe dos pontos que não estão no plano dominante é, então, estimado por um processo de estimação plano 3D + paralaxe, descrito em [18].

Quando a cena é composta por diferentes camadas distribuídas em algumas poucas profundidades diferentes, basta utilizar múltiplos modelos $2 \mathrm{D}$ com os resíduos de paralaxe 3D.

Szeliski [48] propõe uma combinação de alinhamento global e local para criar mosaicos com boa qualidade. $\mathrm{O}$ alinhamento local minimiza a diferença na intensidade entre os pares de imagens após uma determinada transformação (transformação projetiva 2D, por exemplo). Uma vantagem deste método é que ele não precisa identificar características da imagem. Como este algoritmo só encontra a melhor solução local, caso o movimento entre os quadros sucessivos for grande, deve-se utilizar um alinhamento global para corrigir o erro acumulado na seqüência de imagens.

Kang, Cohen e Medioni [21] introduziram um método usando grafos para representar os relacionamentos espaciais e temporais. Esse método visa superar a deficiência no alinhamento global, ou seja, o erro acumulado após sucessivos alinhamentos locais. Cada nó do grafo representa um quadro da seqüência de imagens. Um arco é criado entre dois nós se os quadros correspondentes forem adjacentes no tempo (produz um grafo linear) ou no espaço (se houver sobreposição entre os quadros). Assim, o alinhamento global é obtido por meio da busca do caminho ótimo do grafo construído. Posteriormente, Hsu, Sawhney e Kumar [14] também utilizaram grafos para representar uma topologia deduzida (topology inference) da seqüência de quadros, que serve como estimativa inicial no alinhamento local e posterior alinhamento global.

$\mathrm{Na}$ próxima seção são apresentadas com mais detalhes duas técnicas clássicas de estimação de parâmetros a fim de exemplificar o processo de estimação de movimento.

\subsubsection{Estimação do movimento para cenas 2D}

Szeliski [48] propôs um método para minimizar diretamente a discrepância na intensidade entre pares de imagens depois de aplicar uma transformação afim. Esse 
método não requer a existência de características facilmente identificáveis, ou seja, utiliza informação de todos os pixels para estimar o movimento da câmera (método direto).

Dadas duas imagens (de referência e de inspeção), alinha-se essas imagens utilizando o seguinte modelo de transformação:

$$
x_{i}^{\prime}=\frac{m_{0} x_{i}+m_{1} y_{i}+m_{2}}{m_{6} x_{i}+m_{7} y_{i}+1}, \quad y_{i}^{\prime}=\frac{m_{3} x_{i}+m_{4} y_{i}+m_{5}}{m_{6} x_{i}+m_{7} y_{i}+1}
$$

onde $m_{j}, j=0 \ldots 8$, são os parâmetros de movimento das coordenadas homogêneas da matriz MbD descrita em $(2.1),\left(x_{i}, y_{i}\right)$ é a coordenada do pixel $i$ na imagem de referência e $\left(x_{i}, y_{i}\right)$ é a coordenada do pixel $i$ correspondente na imagem de inspeção .

Essa técnica utiliza uma medida de similaridade que visa minimizar a soma dos quadrados das diferenças de intensidade entre os pixels da região sobreposta, chamada SSD (Sum of the Squared Differences), que é dada por:

$$
E=\sum_{i}\left[I^{\prime}\left(x_{i}^{\prime}, y_{i}{ }^{\prime}\right)-I\left(x_{i}, y_{i}\right)\right]^{2}=\sum_{i} e_{i}^{2}
$$

onde $I\left(x_{i}, y_{i}\right)$ representa a intensidade do pixel $i$ da imagem de referência, $I^{\prime}\left(x_{i}^{\prime}, y^{\prime}\right)$ representa a intensidade do pixel $i$ da imagem de inspeção e os valores de $i$ definem a região sobre a qual a função $E$ é calculada.

Para minimizar a função $E$ descrita em (2.11), utiliza-se o algoritmo iterativo de minimização não-linear de Levenberg Marquardt [39]. Tal algoritmo requer o cálculo das derivadas parciais de $e_{i}$ em relação aos parâmetros de movimento desconhecidos $m_{j}, j=$ $0 . .7$, que é dado por:

$$
\frac{\partial e_{i}}{\partial m_{0}}=\frac{x_{i}}{D_{i}} \frac{\partial I^{\prime}}{\partial x^{\prime}}, \ldots, \frac{\partial e_{i}}{\partial m_{7}}=-\frac{y_{i}}{D_{i}}\left(x_{i}^{\prime} \frac{\partial I^{\prime}}{\partial x^{\prime}}+y_{i}^{\prime} \frac{\partial I^{\prime}}{\partial y^{\prime}}\right)
$$

onde $D_{i}$ é o denominador em (2.10) e (?'/? $/ \mathrm{x}^{\prime}$, ?' $\mathrm{I}^{\prime} /$ y') o gradiente da intensidade da imagem de $I^{\prime}$ em $\left(x_{i}, y_{i}^{\prime}\right)$. A partir dessas parciais, o algoritmo LevenbergMarquardt calcula a matriz Hessiana $A$ e o vetor gradiente $b$ com os componentes: 


$$
a_{k l}=\sum_{i} \frac{\partial e_{i}}{\partial m_{k}} \frac{\partial e_{i}}{\partial m_{l}}, \quad b_{k}=-2 \sum_{i} e_{i} \frac{\partial e_{i}}{\partial m_{k}}
$$

onde $k$ e $l$ são os índices da matriz Hessiana e $i$ define os pixels da região sobreposta.

Finalmente, atualiza-se os parâmetros estimados de movimento $\boldsymbol{m}$ com a quantidade $? m=(A+? I)^{-1} b$, em que ? é um parâmetro de estabilização que varia a cada iteração. Esse algoritmo converge em poucas iterações.

Portanto, o algoritmo completo de alinhamento consiste nos seguintes passos:

1. Para cada pixel $i$ com coordenada $\left(x_{i}, y_{i}\right)$,

- Calcule a posição correspondente na outra imagem $\left(x_{i}^{\prime}, y_{i}^{\prime}\right)$ utilizando (2.10);

- Calcule o erro na intensidade entre os pixels correspondentes $e_{i}=I^{\prime}\left(x_{i}, y_{i}\right)$ $I\left(x_{i}, y_{i}\right)$ e o gradiente da intensidade $\left(? I^{\prime} / ? x^{\prime}, ? I^{\prime} / ? y^{\prime}\right)$;

- Calcule as derivadas parciais de $e_{i}$ sobre $m_{k}$ usando:

$$
\begin{aligned}
& ? e_{i}=\underline{?} \underline{? x}^{\prime}+\underline{?} \underline{?}^{\prime} \underline{y}^{\prime} \\
& ? m_{k} ? x^{\prime} ? m_{k} \quad ? y^{\prime} ? m_{k} \quad \text { como em (2.12); }
\end{aligned}
$$

- Adicione a contribuição do pixel em $A$ e $b$ como em (2.13).

2. Solucione o sistema de equações $(A+? I) ? m=b$ e atualize a estimativa de movimento $m^{(t+1)}=m^{(t)}+? m$.

3. Verifique se o erro em (2.11) diminuiu. Senão, incremente ? e calcule o novo ? $m$.

4. Continue a iteração até que o erro fique menor que o limite mínimo estipulado ou quando atingir um número fixo de passos.

\subsubsection{Mosaico manifold}

A projeção manifold, descrita por Peleg e Herman em [36][40][41], propõe superar as dificuldades na criação de mosaicos quando o movimento da câmera vai além de simples 
translações ou rotações ao redor do eixo óptico, e lidar com distorções existentes quando a câmera encontrase perto da cena 3D.

Essa projeção simula a varredura da cena com um plano, usando um conjunto de sensores unidimensionais. Esses sensores 1D podem varrer a cena por meio de combinações arbitrárias de rotações e translações, e em todos os casos a varredura vai resultar em uma imagem panorâmica razoável caso seja possível descobrir como alinhar as tiras de imagens 1D obtidas (1D image strips).

Algumas imagens de satélites são criadas pela varredura da superficie da Terra com um conjunto de sensores 1D utilizando um espelho giratório, de modo que o alinhamento desses sensores pode ser feito utilizando a localização do satélite e a posição do espelho, obtendo-se facilmente imagens panorâmicas desta cena.

Em casos mais gerais, o movimento do plano de varredura pode não ser conhecido. Parece impossivel alinhar tiras de imagens ID provenientes de planos arbitrários, mas o problema torna-se mais fácil quando a entrada é uma seqüência de vídeo. Um quadro 2D em uma seqüência de vídeo pode ser considerado como tendo uma tira $1 D$ em algum lugar no centro da imagem (center strip - tira central), embutido em uma imagem 2D para facilitar o alinhamento. O movimento do plano de varredura pode ser calculado para a imagem inteira e aplicado na tira central para alinhamento e geração de mosaicos.

As transformações de imagens provenientes de tiras ID geradas pelo plano de varredura são somente transformações rígidas: translações e rotações. Por isso, transformações rígidas devem ser as transformações utilizadas na projeção manifold. Deve-se notar que movimentos da câmera induzem, em geral, transformações de imagem-plano não-rígidas. Entretanto, para simular o plano de varredura, somente transformações rígidas devem ser usadas para a tira central.

Os mosaicos gerados pela combinação do alinhamento $1 \mathrm{D}$ das tiras centrais formam uma nova projeção cena-para-imagem, chamada projeção manifold. Essa projeção é sobre um plano multiforme liso passando através dos centros dos planos utilizados na criação de mosaicos.

Existem três diferentes casos na projeção manifold:

a. No caso de pura translação da câmera, a projeção manifold resulta em uma projeção paralela no plano (ver Figura 2.4.a); 
b. No caso de pura rotação da câmera, resulta em uma projeção em um cilindro, como mostra a Figura 2.4.b;

c. Quando tem-se tanto translação quanto rotação, o manifold resulta em algo mais complexo, como mostrado na Figura 2.4.c.
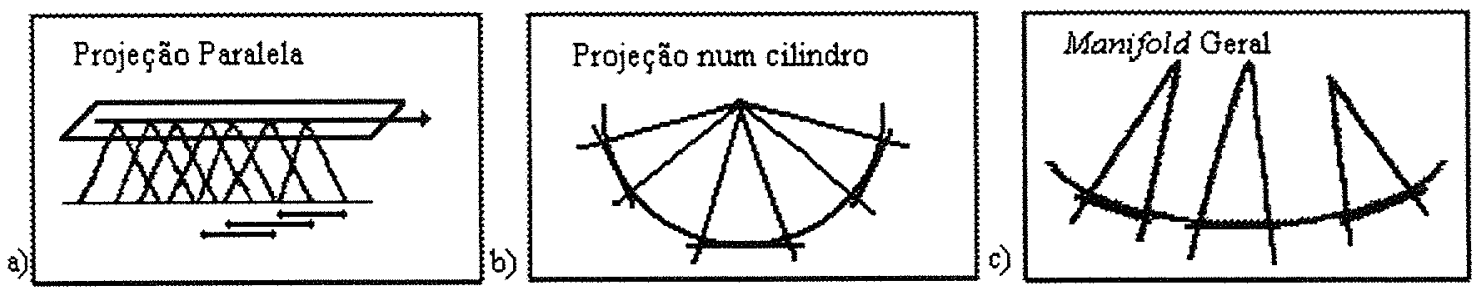

Figura 2.4: a câmera é localizada na extremidade do campo de visão do cone e o plano da imagem é marcado pelo segmento em negrito. (a) é projeção paralela, (b) é projeção em um cilindro e (c) é manifold geral.

A habilidade de lidar com tais combinações arbitrárias de rotação e translação da câmera é a maior diferença entre a projeção manifold e os outros métodos vistos anteriormente.

Para fazer o alinhamento, a simulação da varredura da cena por um plano a partir de uma seqüência de vídeo pode ser feita, uma vez que o movimento $3 \mathrm{D}$ da câmera em relação à cena (ego-motion) é conhecido. Dado o movimento próprio $3 \mathrm{D}$ e dada a série de objetos na qual a relação da altura pela largura das formas dos pixels seja a melhor, é possivel determinar para cada imagem onde a tira ID deve ser alinhada e colada no mosaico.

Entretanto, para os casos simples, ou mesmo para alguns casos mais complexos, a projeção manifold pode ser construída sem o cálculo do movimento próprio, desde que se utilize um bom método de alinhamento de imagens 2D.

Peleg e Herman criaram um software cha mado VideoBrush [37] que gera imagens panorâmicas utilizando a projeção manifold. 


\subsection{Estimação dos parâmetros de movimento}

Nesta seção, serão apresentadas as soluções adotadas para implementar um algoritmo rápido e robusto (utilizado no sistema implementado no decorrer desta dissertação) a fim de se estimar os parâmetros de movimento da câmera.

Utilizando o modelo de transformação perspectiva (seção 2.1.3), o problema de estimar o movimento da câmera consiste em obter os parâmetros de transformação que mapeiam o movimento a partir de pontos correspondentes nas imagens, representados por $\mathbf{R}$ e T na equação (2.7).

Dado um conjunto $S_{i}$ de $N$ características no quadro $f_{i}$ e o conjunto $S_{j}$ dos pontos correspondentes no quadro $f_{j}$, os parâmetros dos modelos $2 \mathrm{D}$ são estimados utilizando-se o método descrito a seguir.

Iniciando com o modelo euclidiano (fator de escala $s=1$ ) e assumindo pequena rotação entre os quadros, os termos trigonométricos de (2.8) podem ser linearizados para se obter:

$$
\left(\begin{array}{c}
x_{i k} \\
y_{i k}
\end{array}\right)=1\left(\begin{array}{cc}
1 & -\theta \\
\theta & 1
\end{array}\right)\left(\begin{array}{c}
x_{j k} \\
y_{j k}
\end{array}\right)+\left(\begin{array}{c}
\Delta x \\
\Delta y
\end{array}\right), k=\{1, \ldots, N\}
$$

Usando (2.14) para todos os $N$ pares de pontos encontrados, um sistema de $2 N$ equações lineares em três variáveis (?, ?x, e ?y) é obtido. Reorganizando (2.14) na forma de matriz, tem-se:

$$
\bar{b}=\overline{A x}, \quad \bar{b}=\left(\begin{array}{c}
x_{i 1}-x_{j 1} \\
y_{i 1}-y_{j 1} \\
\vdots \\
x_{i V}-x_{j N} \\
y_{i \mathrm{~V}}-y_{j N}
\end{array}\right) ; \quad A=\left(\begin{array}{ccc}
-y_{j 1} & 1 & 0 \\
x_{j 1} & 0 & 1 \\
& \vdots & \\
-y_{j N} & 1 & 0 \\
x_{j N} & 0 & 1
\end{array}\right) ; \quad \bar{x}=\left(\begin{array}{l}
\theta \\
\Delta x \\
\Delta y
\end{array}\right)
$$

onde $\bar{x}$ pode ser calculado utilizando a equação normal $\bar{x}=\left(A^{t} A\right)^{-1} A^{t} \bar{b}$. 
O fator de escala $s$ pode ser calculado independentemente para encaixar no modelo de similaridade e, então, ser substituído em (2.15) para estimar os parâmetros remanescentes. Zheng e Chellappa [55] mostram que $s$ é invariante para translação e rotação e inversamente proporcional à proporção da distância entre dois pontos arbitrários da imagem nos tempos $t_{i}$ e $t_{j}$. Mas, $s$ também pode ser obtido considerando quaisquer dois pontos da imagem obtidos em $t_{i}$ e $t_{j}$. Para estimar $s$ a partir dos conjuntos das características correspondentes, considere primeiramente as distâncias com respeito ao centro de massa de cada conjunto. A posição do centro é dada por:

$$
\bar{x}_{f}=\frac{1}{N} \sum_{k=1}^{N} x_{f k}, \quad \bar{y}_{f}=\frac{1}{N} \sum_{k=1}^{N} y_{k k}
$$

onde $\left.\overline{(x}_{f}, \bar{y}_{f}\right)$ são coordenadas do centro de massa do conjunto $S_{f}$ de características e $\left(x_{f k}\right.$, $y_{f k}$ ) são as coordenadas da característica $k$ da imagem no quadro $f$. Seja $\boldsymbol{d}_{f k}$ a distância da característica $k$ ao centro de massa do quadro $f$, de modo que a escala entre os dois quadros $i$ e $j$ pode ser computado por:

$$
\begin{gathered}
\left(\begin{array}{c}
\delta_{i 1} \\
\delta_{i 2} \\
\vdots \\
\delta_{i N}
\end{array}\right)=s\left(\begin{array}{c}
\delta_{j 1} \\
\delta_{j 2} \\
\vdots \\
\delta_{j N}
\end{array}\right) \Rightarrow s=\left[\left(\begin{array}{c}
\delta_{j 1} \\
\delta_{j 2} \\
\vdots \\
\delta_{j N}
\end{array}\right)^{t}\left(\begin{array}{c}
\delta_{j 1} \\
\delta_{j 2} \\
\vdots \\
\delta_{j N}
\end{array}\right)\right]^{-1}\left(\begin{array}{c}
\delta_{j 1} \\
\delta_{j 2} \\
\vdots \\
\delta_{j N}
\end{array}\right)^{t}\left(\begin{array}{c}
\delta_{i 1} \\
\delta_{i 2} \\
\vdots \\
\delta_{i N}
\end{array}\right) \\
\Rightarrow s=\frac{\sum_{k=1}^{N} \delta_{j k} \delta_{k}}{\sum_{k=1}^{N} \delta_{j k} \delta_{j k}}
\end{gathered}
$$

O cálculo dos parâmetros de translação e rotação segue a estimação do fator de escala.

Para o caso afim, as $2 \mathrm{~N}$ equações podem ser escritas como: 


$$
\left(\begin{array}{c}
x_{i 1} \\
\vdots \\
x_{i N} \\
y_{i 1} \\
\vdots \\
y_{i N}
\end{array}\right)=\left(\begin{array}{cccccc}
x_{j 1} & y_{j 1} & 1 & 0 & 0 & 0 \\
\vdots & \vdots & \vdots & \vdots & \vdots & \vdots \\
x_{j N} & y_{j N} & 1 & 0 & 0 & 0 \\
0 & 0 & 0 & x_{j 1} & y_{j 1} & 1 \\
\vdots & \vdots & \vdots & \vdots & \vdots & \vdots \\
0 & 0 & 0 & x_{j N} & y_{j N} & 1
\end{array}\right)\left(\begin{array}{c}
x_{11} \\
r_{12} \\
\Delta x \\
r_{21} \\
r_{22} \\
\Delta y
\end{array}\right)
$$

Está claro que a solução para (2.17) pode ser obtida solucionando dois sistemas lineares $3 \times 3$ utilizando a mesma técnica aplicada para solucionar os parâmetros euclidianos.

Assim, foi descrito como se calcula o movimento 2D rígido da câmera, assumindo que existe um conjunto de $\mathrm{N}$ pares de características correspondentes.

A próxima seção descreve os métodos utilizados para extrair, selecionar e rastrear as características.

\subsection{Extração de características}

O primeiro passo para se extrair as características de uma imagem é construir uma pirâmide Gaussiana e, a partir desta, construir uma pirâmide Laplaciana. A imagem resultante da pirâmide Laplaciana possui os contornos dos objetos realçados, facilitando assim a seleção das características. Desse modo, primeiramente é detalhada a geração dessas pirâmides [6] e posteriormente é descrito o processo de seleção e rastreamento das características.

\subsubsection{Pirâmide Gaussiana}

Suponha que uma imagem é representada por uma matriz $g_{0}$ de pixels que contém $\mathrm{C}$ colunas e $\mathrm{R}$ linhas e cada pixel é representado por três componentes (RGB), que 
correspondem às cores vermelho, verde e azul, respectivamente. Essa imagem é a base ou nível zero da pirâmide Gaussiana. O nível 1 da pirâmide contém a imagem $g_{l}$, que é uma versão reduzida da imagem $g_{0}$. De fato, cada valor dentro do nível 1 é obtido por meio da aplicação de um filtro (uma média com peso) nos valores do nível 0 . Da mesma forma, cada valor dentro do nível 2, representando $g_{2}$, é obtido a partir dos valores do nível 1 (após a aplicação do mesmo filtro). Uma representação gráfica desse processo em uma dimensão (somente para a componente verde da imagem, por exemplo) é mostrada na Figura 2.5. Foi escolhida uma máscara (janela) de tamanho $5 \times 5$ porque ela fornece um filtro adequado a um baixo custo computacional.

O processo de redução nível a nível é realizado pela função REDUZ.

$$
g_{l}=\operatorname{REDUZ}\left(g_{l-1}\right)
$$

que significa que, sendo $N$ igual ao número de níveis da pirâmide e $C_{l}$ e $R_{l}$ iguais às dimensões do $l$-ésimo nível, para os níveis $0<l<N$ e os nós $i, j, 0<i<C_{l}, 0=j<R_{l}$,

$$
g_{l}(i, j)=\sum_{m=-2}^{2} \sum_{n=-2}^{2} w(m, n)_{g l-1}(2 i+m, 2 j+n)
$$

onde $w$ é um filtro Gaussiano [5].

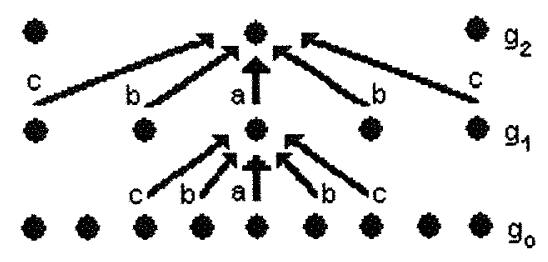

$$
\begin{aligned}
& \mathrm{g}_{0}=\text { imagem original } \\
& \mathrm{g}_{\mathrm{L}}=\operatorname{Reduz}\left(\mathrm{g}_{\mathrm{L}-1}\right)
\end{aligned}
$$

Figura 2.5: representação gráfica do processo (em uma dimensão) que gera a pirâmide Gaussiana. Cada linha de pontos representa os nós dentro de um nível da pirâmide. $O$ valor de cada nó no nivel zero corresponde a uma das componentes $(R, G$ ou $B)$ do pixel da imagem original. $O$ valor de cada nó no nível superior é a média com peso dos valores dos nós do nível inferior subseqüente (função REDUZ). Note que o espaçamento duplica de nível para nivel, enquanto o mesmo filtro é usado na geração de todos os níveis. 


\subsubsection{Interpolação da pirâmide Gaussiana}

É preciso definir também uma operação inversa à função REDUZ, chamada EXPANDE. Tal função expande uma matriz $(R+l)$ por $(C+l)$ para uma matriz $(2 R+$ l) por $(2 C+I)$, interpolando novos valores para os nós entre os valores dados. Dessa maneira, a função EXPANDE, aplicada à matriz $g_{l}$ da pirâmide Gaussiana, produz uma matriz $g_{l, l}$, que é do mesmo tamanho de $g_{l-l}$.

Seja $g_{l, n}$ o resultado da expansão de $g_{l}, n$ vezes, então,

$$
g_{l, 0}=g_{l}
$$

e

$$
g_{l, n}=\operatorname{EXPANDE}\left(g_{l}, n-l\right)
$$

onde EXPANDE significa, para os níveis $0<l=N$ e $0=n$ e os nós $i, j, 0=i<C_{l-n}, 0=j$ $=R_{-n}$,

$$
g_{l, n}(i, j)=4 \sum_{m=-2}^{2} \sum_{n=-2}^{2} w(m, n) \unrhd g_{l, n-1}\left(\frac{i-m}{2}, \frac{j-n}{2}\right)
$$

Só são incluídos nessa soma os termos nos quais $(i-m) / 2$ e $(j-n) / 2$ são inteiros. Se for aplicado EXPANDE $l$ vezes na imagem $g_{l}$, obtém-se $g_{l, l}$, que é do mesmo tamanho da imagem original $g_{0}$.

\subsubsection{Pirâmide Laplaciana}

Uma vez definida a função EXPANDE e calculada a pirâmide Gaussiana, é possível gerar a pirâmide Laplaciana, que é definida por uma seqüência de imagens $L_{\emptyset}, L_{1}, \ldots, L_{N}$, onde cada imagem é a diferença entre dois níveis da pirâmide Gaussiana, ou seja, é o resultado da diferença da expansão de $g_{l+1}$ por $g_{i}$. Assim, para $0=I<N$, 


$$
L_{l}=g_{l}-\operatorname{EXPANDE}\left(g_{l+1}\right)=g_{l}-g_{l+1, l}
$$

A imagem Laplaciana, resultante dessa diferença, também é conhecida como imagem de erro, pois contém as informações que foram perdidas durante a aplicação do filtro e durante a redução e expansão da image $m$.

Para ilustrar este processo, pode-se observar na Figura 2.6 um exemplo das imagens utilizadas na construção do nível 1 da pirâmide Laplaciana . Assim, a primeira imagem (à esquerda) representa uma redução da imagem original $(320 \times 160)$, ou seja, uma imagem com tamanho $160 \times 120$. A segunda imagem (ao centro) é o resultado da aplicação do filtro Gaussiano com redução, onde foi utilizada uma máscara de tamanho $5 \times 5$, e posterior expansão desta. A terceira imagem (à direita) é o inverso do resultado do módulo da subtração pixel por pixel da primeira imagem pela segunda.

Assim, pode-se observar um exemplo de uma pirâmide Gaussiana (Figura 2.7.b) e uma pirâmide Laplaciana (Figura 2.7.c) como três níveis, onde os níveis 0,1 e 2 foram gerados repetindo-se o processo exemplificado na Figura 2.6. a partir da imagem original com tamanho $320 \times 240$ e suas reduzidas, com tamanho $160 \times 120$ e 80x60 (Figura 2.7.a), respectivamente.

Na representação das imagens resultantes do processo de construção da Laplaciana, é utilizado o módulo da subtração das imagens, pois o valor de um pixel de uma imagem é sempre positivo. Além disso, é utilizado o inverso da imagem resultante da subtração para facilitar a visualização das bordas existentes na imagem. Entretanto, a seleção das características é realizada na imagem Laplaciana representada por uma matriz com valores inteiros, como descrito na próxima seção.
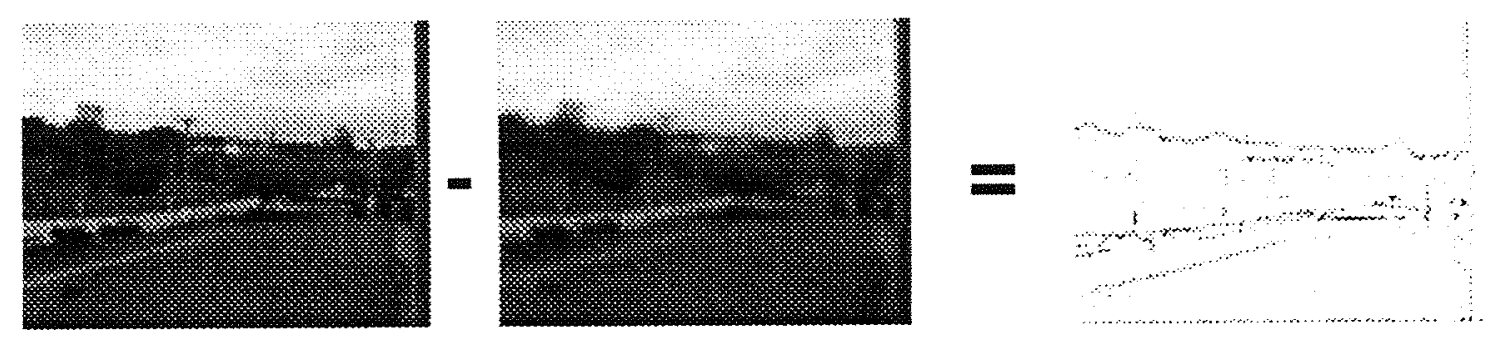

Figura 2.6: processo de construção da imagem Laplaciana - a primeira imagem (à esquerda) representa a imagem original, a segunda imagem (ao centro) é o resultado da 
aplicação do filtro Gaussiano com redução e posterior expansão desta e a terceira imagem (à direita) é o inverso do resultado da subtração da primeira imagem pela segunda. 


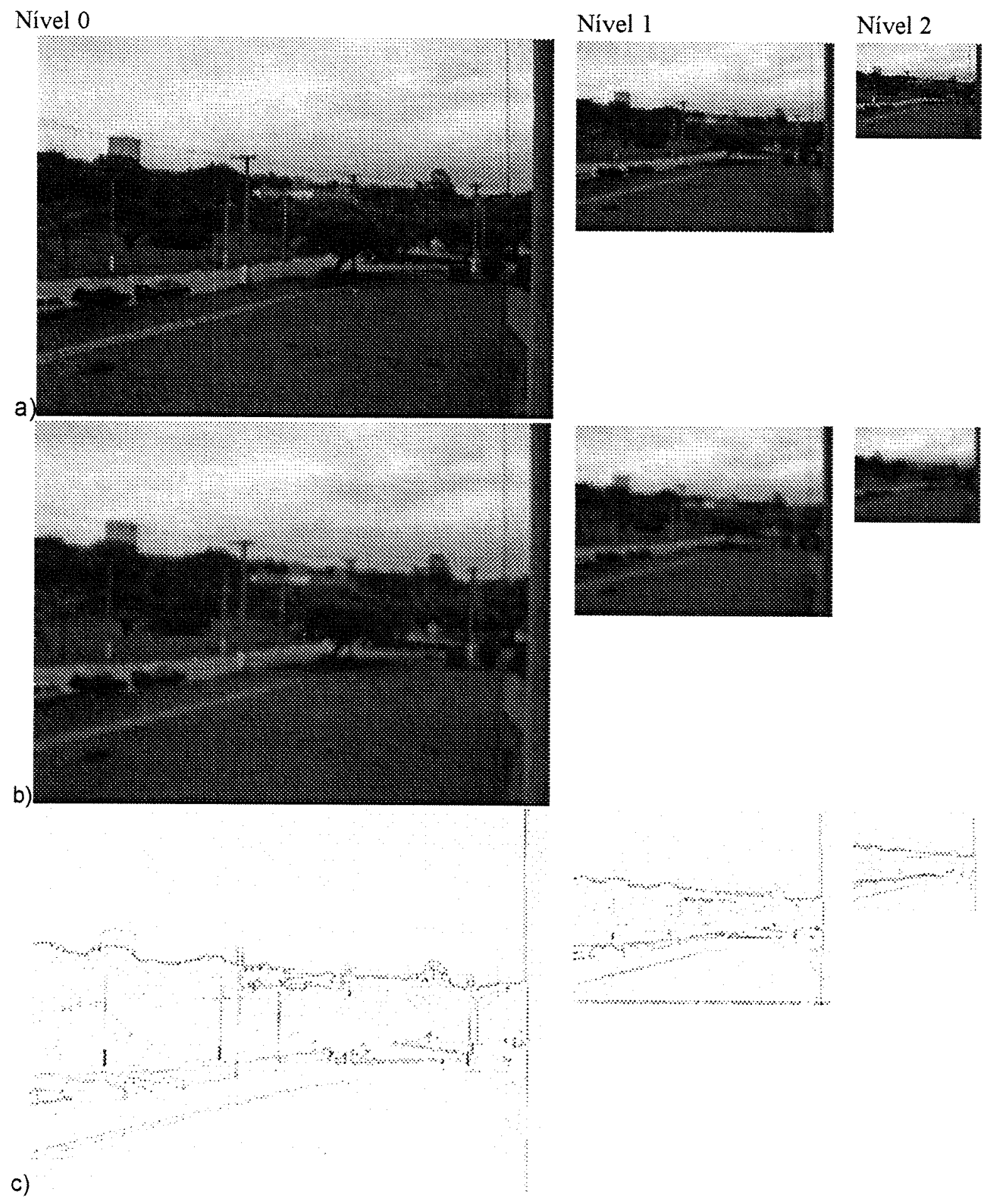

Figura 2.7: Pirâmides com três niveis:

a) Pirâmide com imagem original e reduzidas;

b) Pirâmide Gaussiana;

c) Pirâmide Laplaciana (inverso dos valores absolutos). 


\subsubsection{Seleção das características a partir da Laplaciana}

Conforme foi visto na seção anterior, as imagens resultantes da construção da pirâmide Laplaciana possuem os contornos realçados, facilitando a seleção de características que correspondam, por exemplo, a cantos, sendo que cantos são pontos onde o gradiente é suficientemente al to em duas direções ortogonais [45].

A seleção das características é realizada na imagem Laplaciana representada por uma matriz de valores inteiros (que corresponde a segunda derivada da imagem original). A imagem Laplaciana representada na figura 2.7.c é apenas ilustrativa. Dessa forma, é realizada uma busca por cruzamentos em zero (zero crossings) nessa matriz de inteiros, nos quais (esses cruzamentos) indicam a posição de bordas [57]. Assim, o pixel com valor acima de um determinado limiar positivo, e que possua, numa região $3 \times 3$, a maior parte dos vizinhos com intensidade negativa é selecionado para o rastreamento. $O$ inverso também é verdade, ou seja, o pixel com intensidade menor que o negativo deste limiar e que possua, numa região $3 \times 3$, a maior parte dos vizinhos positivos, também é selecionado para o rastreamento.

Uma característica pode ser selecionada baseada em algumas medidas de textura, como alto padrão de variação no modelo de intensidade espacial, a presença de intersecção de zeros na intensidade da imagem Laplaciana ou cantos.

Uma característica é considerada boa se ela corresponde a pontos físicos no mundo real. Por exempb, em uma imagem de uma árvore, um graveto horizontal da parte da frente da árvore pode intersectar um graveto vertical do fundo. Essa intersecção ocorre somente na imagem, não no mundo real, pois os dois gravetos estão em profundidades diferentes. Assim, qualquer critério de seleção de características poderia pegar essa intersecção como uma boa característica, mas ela não corresponde a uma característica do mundo real e, ao tentar buscar esta característica em uma imagem desta árvore obtida por outro ângulo, tal interseç̧ão pode não existir mais. Para descartar essas características ruins, pode-se utilizar a medida da dissimilaridade da característica, que quantifica as mudanças em suas aparências entre os quadros da seqüência de imagens. Se a dissimilaridade aumenta muito, essa característica deve ser abandonada. 


\subsection{Rastreamento das características}

Após a seleção das características no quadro $f_{t-l}$, elas são rastreadas no quadro $f_{t}$, utilizando a medida de similaridade definida pela SSD sobre janelas locais centralizadas nos pontos das características, em um esquema de refinamento que trabalha do nível mais alto até a base da pirâmide Gaussiana. Essa medida de similaridade é calculada sobre uma vizinhança (janela de busca) ao redor dos candidatos a serem combinados no quadro $f_{t}$, e o ponto que retorna o menor SSD é selecionado como a melhor combinação.

O SSD entre duas janelas de tamanho $W=(2 w+1) x(2 w+1)$, centralizada no ponto $P_{t-l}(x, y)$ da imagem do quadro $f_{t-l}$ e no ponto $P_{t}(u, v)$ da imagem do quadro $f_{t}$ é dado por:

$$
\mathrm{SSD}=\sum_{i, j}\left[\left(P_{t-1}(x+i, y+j)-P_{t}(u+i, v+j)\right)^{2}\right], \quad i, j \in[-w,+w]
$$

onde $P_{t-1}(x, y)$ representa o valor da intensidade luminosa do pixel com coordenada $(x, y)$ da imagem do quadro $f_{t-1}, P_{t}(u, v)$ representa o valor da intensidade luminosa do pixel com coordenada $(u, v)$ da imagem do quadro $f_{t-1}$ e o tamanho da janela de correlação $(W)$ geralmente é $5 \times 5$ ou $7 \times 7$, dependendo do nível de detalhamento desejado.

Uma pirâmide Gaussiana $G_{t}$ é formada pela combinação de diversas imagens de resolução reduzida do quadro $f_{t}$ (após aplicação do filtro de Gauss). Cada nível da pirâmide vai ser denotado por $G_{t}^{l}$, onde $G_{t}{ }^{0}$ é a imagem Gaussiana da imagem original do quadro $f_{t}$, ou seja, corresponde a matriz $g_{0}$ definida na seção 2.4.1. Como o rastreamento é feito pela maneira hierárquica na pirâmide Gaussiana, cada nível de cada pirâmide $G_{t-1}$ e $G_{t}$ contribui para determinar a posição da característica que será combinada.

Assuma que as pirâmides têm $j+1$ níveis (de 0 a $j$ ), e o nível $j$ tem a menor resolução. Depois que as características são selecionadas usando $L^{j}{ }_{t \cdot 1}$ (a imagem Laplaciana de $G^{j}{ }_{k-1}$ ), cada caracteristica é utilizada para encontrar sua correspondente em $G_{t}^{\prime}$. Para a característica $P_{t-1}^{\prime}(x, y)$ de $L_{t-1}^{j}$, uma busca pelo SSD minimo é realizada sobre a janela de busca de tamanho $S=(2 s+1) x(2 s+1)$ centralizada no pixel $P^{\prime}(x, y)$ de $G_{t}^{\prime}$. Seja 
$P_{t}^{j}(u, v)$ a característica rastreada correspondente à característica $P_{t-1}^{j}(x, y)$. Observe que o deslocamento máximo suportado por essa busca é somente $s$ pixels. Para o próximo nível da pirâmide, as coordenadas desses pares são ampliados pelo fator 2. Para a característica $P^{j-1}{ }_{t-1}(2 x, 2 y)$, a busca pelo SSD mínimo é realizada, agora, ao redor do pixel $P^{j-1}{ }_{t}(2 u, 2 v)$. Tal processo é repetido até que o nível zero seja alcançado (maior resolução). Note que, como o deslocamento é duplicado após cada nível, o deslocamento total que o algoritmo pode manipular pode ser muito grande, mesmo para valores pequenos de $s$.

Um exemplo do processo de rastreamento em apenas um dos níveis da pirâmide está representado na figura 2.8 .
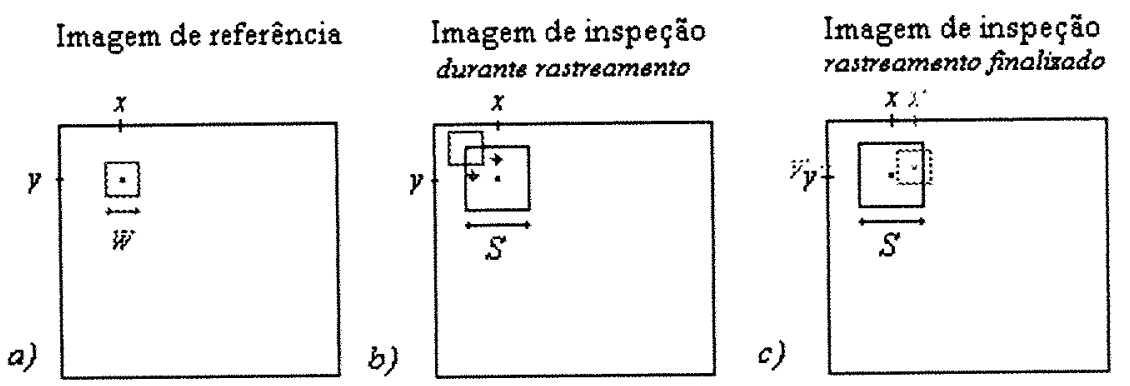

Figura 2.8: Rastreamento de $p(x, y)$ na imagem de inspeção - calcula-se o SSD entre a janela de correlação (vermelha, com tamanho $W$ centrada no ponto $p(x, y)$ da imagem de referência, representada em (a)), e todas as possíveis janelas de correlação, representada em vermelho em (b), com o mesmo tamanho $W$, centradas em cada pixel da imagem de inspeção que esteja dentro da janela de busca (azul, com tamanho $S$ e centrada em $p(x, y)$ ). $\mathrm{O}$ ponto dentro da janela de busca que retornar o menor SSD é selecionado, como $p^{\prime}\left(x^{\prime}, y^{\prime}\right)$ representado em verde em (c), por exemplo. 


\section{Alinhamento e Integração de Imagens}

$O$ resultado do processo de estimação dos parâmetros de movimento descrito no capítulo anterior é capaz de computar o movimento entre dois quadros. A partir do momento que os parâmetros de movimento foram calculados, é preciso alinhar as sucessivas imagens e integrá-las a fim de se superar as diferenças de intensidade entre as imagens, com o propósito de se obter, dentro do possível, um mosaico sem costuras.

\subsection{Alinhamento seqüencial}

Uma vez que os parâmetros de movimento foram calculados, todos os quadros da seqüência de imagens devem ser alinhados para se gerar o mosaico.

Existem diferentes métodos para realizar esse alinhamento e cada um possui vantagens e desvantagens, dependendo do movimento realizado pela câmera. Os métodos mais utilizados são: 
- Quadro a quadro: o mosaico pode ser construído alinhando os quadros adjacentes, ou seja, cada quadro é alinhado em relação ao quadro anterior (o primeiro quadro pode ser colocado arbitrariamente no mosaico, e o segundo quadro é alinhado com o primeiro, o terceiro com o segundo e assim por diante). Os parâmetros de movimento estimados representam o movimento realizado entre quadros sucessivos. Assim, esses parâmetros podem ser compostos para se obter os parâmetros de alinhamento entre qualquer par de quadros da seqüência.

- Quadro para mosaico: um problema do alinhamento quadro a quadro é que os erros vão se acumulando a cada par de imagens, devido à composição repetida dos parâmetros de alinhamento. Para uma seqüência de imagens em que a câmera realiza uma trajetória retangular e volta ao ponto de origem (Figura 3.1.b), esperava-se que 0 último quadro coincidisse com o primeiro, mas o efeito cumulativo produz um erro significativo na posição do último quadro, como pode ser observado na Figura 3.1.a (tal efeito é conhecido com looping path problem). $\mathrm{O}$ alinhamento pode ser melhorado por um refinamento direto da transformação entre cada quadro e a imagem do mosaico. Para superar o problema do grande deslocamento entre a imagem do mosaico e a nova imagem do quadro, os parâmetros do alinhamento computados entre o quadro anterior e a imagem do mosaico são utilizados como estimativa inicial.

a)

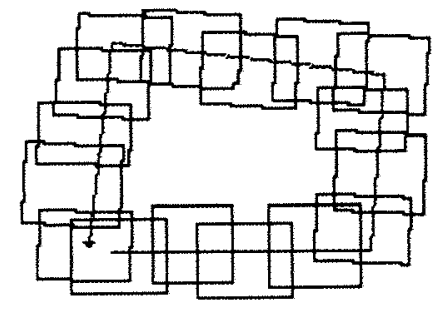

b)

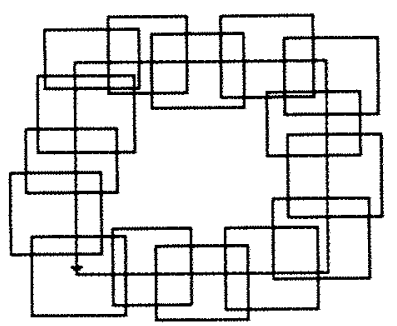

Figura 3.1: looping path problem - seqüência de imagens, em que a câmera realizou um trajetória retangular e voltou a quadro inicial.

a) $\mathrm{O}$ erro acumulado durante o alinhamento quadro a quadro gera um deslocamento grande no último quadro em relação ao primeiro.

b) Alinhamento seqüencial ideal, no qual o último quadro está perfeitamente alinhado com o primeiro. 
- Quadro para grafo: utiliza-se uma representação baseada em grafos, em que cada nó representa um único quadro da seqüência de quadros a ser processada. Um arco é criado entre dois nós se os quadros correspondentes são adjacentes no tempo ou no espaço. A vizinhança temporal (quadros sucessivos) produz um grafo linear. A adjacência espacial é determinada pela sobreposição entre dois quadros. Para se computar a área de sobreposição aproximada, realiza-se um alinhamento seqüencial quadro a quadro, como descrito anteriormente. Um arco entre dois nós é criado somente se a área de sobreposição é significativa e o alinhamento local entre esses dois quadros produzir uma alta correlação. $\mathrm{O}$ alinhamento global é obtido por meio da busca do caminho ótimo do grafo construído [21], [14].

\subsection{Integração das imagens}

Durante $o$ alinhamento seqüencial dos quadros, se eles forem simplesmente colados um sobre o outro, serão produzidas bordas artificiais na junção entre as imagens, devido a diferenças na obtenção das imagens, na iluminação da cena ou devido a erros no alinhamento geométrico.

O objetivo da integração das imagens é produzir um mosaico visualmente agradável, com duas propriedades desejáveis [19]:

- O mosaico deve ser o mais parecido possível com as imagens que o originaram;

- A junção entre as imagens deve ser imperceptível.

Grande parte dos sistemas existentes para se construir mosaicos procura todas as imagens de origem que mapeiem um determinado pixel e utilize alguma função para escolher ou misturar os "melhores" pixels, a fim de integrar as imagens alinhadas [18][35]. Além disso, existem métodos que trabalham com os gradientes da imagem [19], métodos que exploram a reconstrução das propriedades da pirâmide Laplaciana [5], entre outros. Abaixo segue uma lista dos principais métodos existentes: 
1. A informação que é encontrada no quadro mais recente é utilizada para atualizar o mosaico, ou, restringindo mais anda, o mosaico pode ser tratado como uma "memória de somente uma escrita", ou seja, apenas as partes novas da cena são desenhadas sobre o mosaico [28]. Isso é especialmente útil para sistemas em tempo real, pois o uso de filtros provoca aumenta no custo computacional. Entretanto, as junções das imagens geralmente ficam bastante destacadas e os objetos em movimento desaparecem ou ficam truncados, dependendo da posição desses na cena.

2. É utilizado um filtro da média ou mediana temporal dos valores da intensidade das imagens alinhadas [18]. Tanto a média quanto a mediana aplicada na seqüência de imagens alinhadas vai produzir uma imagem panorâmica do plano de fundo dominante da cena, onde objetos em movimento ou desaparecerão ou deixarão rastros "fantasmas". A mediana temporal geralmente resulta em mosaicos menos borrados que aqueles obtidos pela média temporal, pois como a mediana é o valor central da distribuição dos dados, ela não é influenciada por pontos que destoam muito em relação à maioria.

3. É utilizado um filtro da mediana ou média temporal com peso, onde o peso decresce com a distância do pixel em relação à região central do quadro [18]. Esse método visa ignorar imprecisões no alinhamento dos pixels perto da borda da imagem decorrente da utilização de transformações paramétricas 2D com poucos parâmetros, ou devido a distorções da lente.

4. É utilizada uma técnica em multi-resolução [5] (utiliza pirâmide Laplaciana) para integrar as imagens, ou seja, diferentes bandas de frequência são combinadas com diferentes máscaras. Freqüências baixas são misturadas em uma região mais ampla e os detalhes são misturados em uma região menor. Isso produz uma transição gradual em baixa freqüência, enquanto reduz a duplicação dos contornos em regiões com textura. 
5. É utilizado um processo de otimização, que usa os gradientes das imagens para se obter a melhor integração possivel destas [19]. Esse método desenvolvido recentemente, chamado de GIST1, gera o mosaico minimizando uma função de custo $E$, onde $E$ é uma medida de dissimilaridade entre as derivadas da imagem integrada e as derivadas das imagens de origem. Como é utilizado o domínio dos gradientes, em vez do domínio das intensidades (maioria dos métodos), esse método reduz as inconsistências globais entre as imagens unidas devido a mudanças na iluminação. 



\section{Descrição da solução desenvolvida}

Nesta seção, é descrito o algoritmo que foi implementando para se obter o mosaico de uma cena. Este algoritmo foi baseado no sistema implementado por Morimoto [28], no qual é proposto um método baseado na deteç̧ão de características da cena, que utiliza um subconjunto do grupo afim de transformações para modelar o movimento da câmera.

No trabalho original, um sistema para construção de mosaicos foi desenvolvido para rodar em um Datacube MaxVideo 200, uma máquina paralela específica para processamento de imagens, conectada a uma estação SUN SPARCstation 20/612, e trabalhava com imagens em níveis de cinza, no formato PNM e com tamanho $128 \times 128$. Tal sistema foi portado para um microcomputador IBM PC, em ambiente Windows, e foi

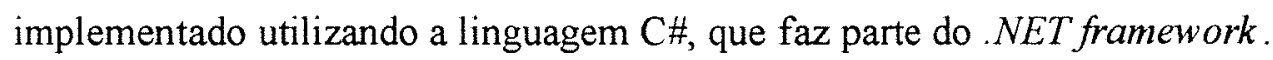

Apesar desse sistema só ser capaz de tratar movimentos rígidos da câmera, nesse trabalho foram estudados modelos mais complexos de transformação e integração de imagens, como os descritos por Peleg e Herman em [36], Szeliski em [48], Burt e Adelson em [5], Hsu, Sawney e Kumar em [14], entre outros, de modo que algumas melhorias foram integradas ao sistema portado.

Foram estudadas também técnicas baseadas em rastreamento de características, a fim de obter mosaicos em tempo real. 
O sistema desenvolvido utiliza a biblioteca gráfica chamada GDI+ para manipulação de imagens. Assim, ele é capaz de tratar imagens que estejam armazenadas em qualquer um dos formatos mais conhecidos (JPEG, BMP, GIF, TIFF, PNG etc.) e não existe restrição quanto ao tamanho das imagens, desde que todas as imagens de uma mesma seqüência possuam dimensões iguais.

Além disso, o sistema é capaz de trabalhar com imagens obtidas diretamente de sequêencias de vídeo nos formatos MPEG ou AVI, ou ainda a partir de imagens obtidas por um dispositivo de captura de vídeo, como uma webcam. Para isso, é utilizado a biblioteca gráfica DirectX.

Os passos básicos realizados pelo sistema desenvolvido são:

- Características são extraídas e rastreadas hierarquicamente entre os quadros consecutivos;

- Deslocamentos entre as características são utilizados para estimar os parâmetros do modelo de movimento, que pode ser refinado entre os níveis da pirâmide;

- O movimento entre os quadros é utilizado para alinhar e combinar o quadro atual com o de referência, gerando o mosaico.

\subsection{Detecção e rastreamento automático de características}

Conforme descrito na seção 2.4 , o primeiro passo para se extrair as características é construir as pirâmides Gaussiana e Laplaciana.O sistema desenvolvido utiliza apenas 2 níveis das pirâmides, como o exemplo representado na figura 4.1. A primeira pirâmide é constituída pela imagem original $(320 \times 160)$ e uma redução da imagem original, ou seja, uma imagem com tamanho $160 \times 120$. A segunda pirâmide (Gaussiana) é o resultado da aplicação de um filtro Gaussiano nas imagens da primeira pirâmide, nos níveis correspondentes, onde foi utilizada uma máscara de tamanho $5 \times 5$ (representada na Tabela 4.1). A terceira pirâmide (Laplaciana) representa o inverso do módulo da subtração pixel 
por pixel das imagens da primeira pirâmide pelas imagens da segunda pirâmide, nos dois níveis correspondentes.

a)
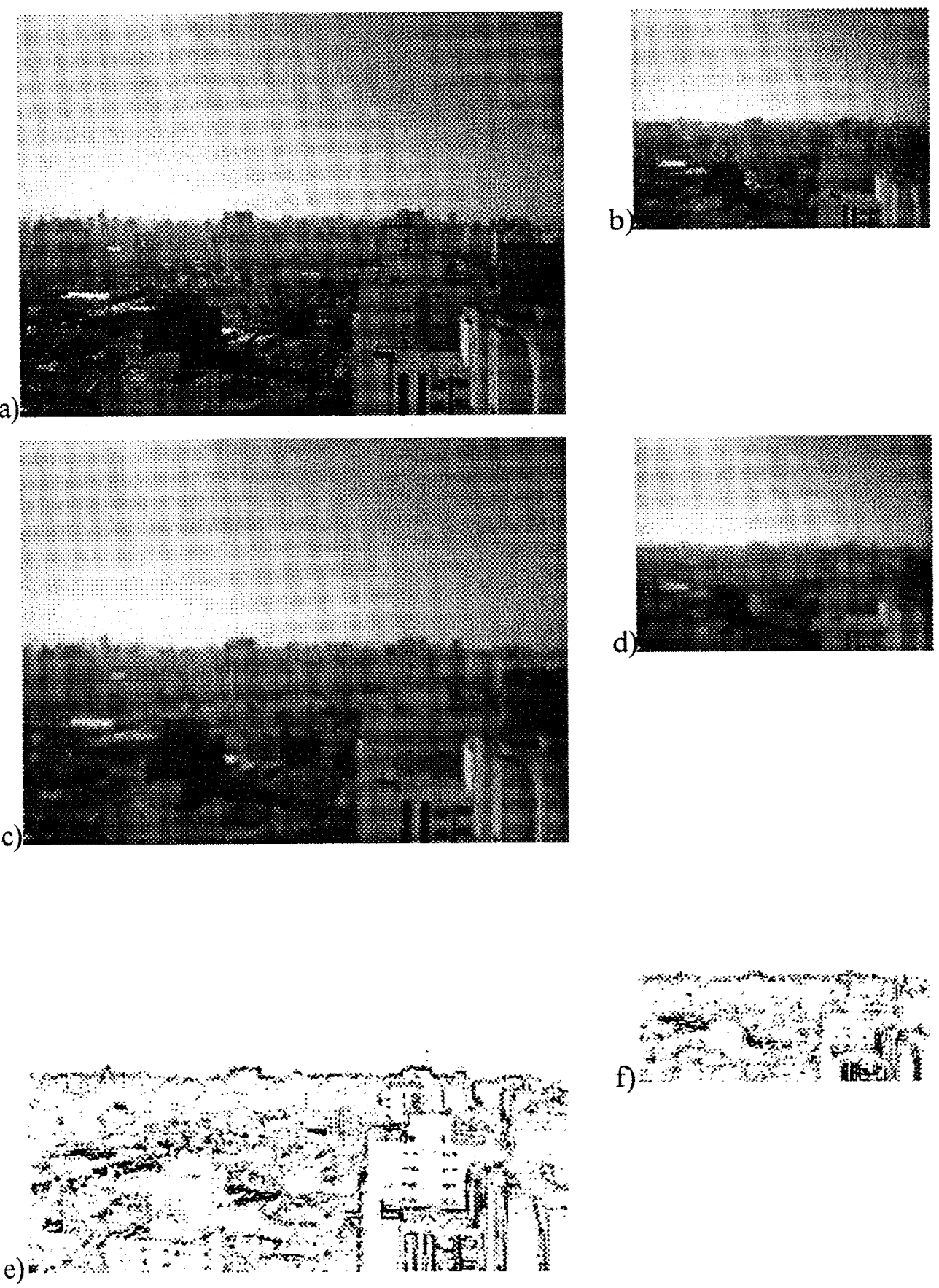

Figura 4.1: pirâmides de 2 níveis utilizadas na detecção de características:

a-b) Pirâmide com a imagem original $(320 \times 240)$ e a imagem reduzida (160×120);

c-d) Pirâmide Gaussiana;

e- f) Negativo da pirâmide Laplaciana. 


\begin{tabular}{|ll|l|l|l|}
\hline 1 & 4 & 6 & 4 & 1 \\
\hline 4 & 16 & 24 & 16 & 4 \\
\hline 6 & 24 & 36 & 24 & 6 \\
\hline 4 & 16 & 24 & 16 & 4 \\
\hline 1 & 4 & 6 & 4 & 1 \\
\hline
\end{tabular}

Tabela 4.1: matriz utilizada no filtro Gaussiano, em que o valor do centro da matriz (36) representa o peso do pixel que está sendo calculado.

A imagem do nível 1 (menor resolução) da pirâmide Laplaciana é dividida em $\mathrm{N}$ partições verticais, onde $\mathrm{N}$ corresponde ao número de caracterís ticas a serem rastreadas, onde o número mínimo de características necessárias para se estimar os parâmetros de movimento é quatro. Cada partição é varrida do topo até a base e o pixel superior com intensidade maior que um limiar definido pelo usuário e que possua, numa região $3 \times 3$, a maior parte dos vizinhos negativos é selecionado para o rastreamento. $O$ inverso também é verdade, ou seja, o pixel superior com intensidade menor que o negativo do limiar definido pelo usuário e que possua, numa região $3 \times 3$, a maior parte dos vizinhos positivos, também é selecionado para o rastreamento (busca por cruzamentos em zero).

Caso a sequência de imagens de entrada for afim em todos os pontos (ex: seqüência de imagens aéreas), o usuário pode alterar (graficamente) os parâmetros do sistema, para que, além das $\mathrm{N}$ tiras verticais, a imagem seja dividida em $\mathrm{M}$ tiras horizontais. A divisão da imagem em regiões elimina a necessidade de utilizar-se um limiar para selecionar as características.

Depois que as características são selecionadas usando o nível 1 da pirâmide Laplaciana do quadro $f_{t-1},\left(L_{\mathrm{k} l}^{1}\right)$, cada característica é utilizada para encontrar sua correspondente em $G_{t}^{l}$. Para a característica $P_{t-l}^{l}(x, y)$ de $L_{t-1}^{l}$, uma busca pelo SSD mínimo é realizada sobre a janela de busca de tamanho $S=(2 s+1) x(2 s+1)$ centralizada no pixel $P^{l}{ }_{t}(x, y)$ de $G^{l}{ }_{t}$. Seja $P^{l}{ }_{t}(u, v)$ a característica rastreada correspondente à característica $P_{t-1}^{l}(x, y)$. As coordenadas desses pares são ampliados pelo fator 2 e a busca pelo SSD mínimo é realizada agora ao redor do pixel $P^{0} t(2 u, 2 v)$, como visto na 
seção 2.5. É possivel alterar graficamente o tamanho desta janela de busca, pois como só é utilizado 2 níveis da pirâmide, caso o deslocamento entre as imagens seja muito grande, é necessário aumentar o tamanho da janela de busca. Quanto maior for o tamanho desta janela de busca, mais lento fica o sistema.

\subsection{Integração das imagens}

A imagem do mosaico é composta pelo alinhamento do quadro atual sobre o mosaico. O mosaico é criado com um tamanho inicial um pouco maior que o tamanho das imagens e o primeiro quadro pode ser colocado arbitrariamente no centro do mosaico, por exemplo. Quando um novo quadro é alinhado fora do mosaico, o mosaico é expandido para que o mosaico gerado contenha to da a cena. Para evitar percorrer todo o mosaico, o qual pode ser consideravelmente maior que o quadro de entrada, os quatro cantos da imagem de entrada são alinhados primeiro, para determinar o retângulo delimitador no mosaico que contém a imagem de entrada alinhada. Assim, somente este retângulo precisa ser varrido.

É possivel utilizar diversos filtros para compor as imagens panorâmicas: usar sempre os pixels do último quadro, calcular a média, a mediana ou usar outras funções, como descrito na seção 3.2 .

Como o sistema desenvolvido visa obter o mosaico em tempo real, utilizar sempre os pixels do último quadro parecia ser uma técnica razoável. Entretanto, ao utilizar tal técnica, observourse grandes descontinuidades nas bordas dos quadros correspondentes do mosaico, devido a pequenos erros no alinhamento, distorções da lente e mudanças na iluminação (ver figura 4.2.a).

Assim, foram desenvolvidos vários refinamentos, a fim de minimizar as bordas artificiais geradas no processo de integração das imagens com um baixo custo computacional. 


\subsubsection{Simplificação do diagrama de Voronoi}

Foi utilizado um filtro em que são escolhidos os pixels de cada imagem que estão mais próximos do centro, devido às seguintes razões:

- O alinhamento é geralmente melhor no centro do que nas bordas da imagem;

- A distorções são mínimas no centro das imagens, devido a distorções das lentes nas bordas.

Esta seleção corresponde ao diagrama de Voronoi [1][34] e visa minimizar o erro no alinhamento devido a distorções da lente, pois faz com que a borda situe-se igualmente distante dos centros correspondentes das imagens. Como as distorções da lente produzem um efeito radial, características perpendiculares à borda vão ser distorcidas igualmente nesta, e, assim, vão permanecer alinhadas apesar da distorção da lente.

A utilização do diagrama de Voronoi no processo de integração de imagens drasticamente muito o efeito da distorção da lente, como pode ser visto em [14][10]. Entretanto, existe um custo computacional muito alto para se estimar a sobreposição existente entre todas as imagens (construir um grafo como descrito na seção 2.2, por exemplo) e posteriormente se calcular o diagrama de Voronoi para todas as imagens que se sobrepõem.

Assim, como o sistema visa gerar imagens panorâmicas em tempo real e o alinhamento seqüencial é realizado entre quadros sucessivos, em vez de calcular o diagrama de Voronoi para toda a seqüência de imagens, calcula-se um "diagrama" de Voronoi entre a última imagem incluída (imagem de referência) no mosaico e a imagem atual sendo alinhada (imagem de inspeção). Dessa forma, só é preciso calcular a mediatriz entre os centros das duas imagens e incluir no mosaico somente os pixels que estão do mesmo lado (da mediatriz) que está o pixel do centro da imagem de inspeção.

Para se descobrir se dois pontos estão localizados no mesmo lado em relação a uma reta, utiliza-se a seguinte propriedade: sejam $p_{1}$ e $p_{2}$ pontos que pertencem ao mesmo plano de uma reta $n$, mas não pertencem a esta. Estes pontos estão do mesmo lado em relação a reta $r_{1}$ (estão ambos à direita ou ambos à esquerda), se o determinante entre $p_{1} \mathrm{e}$ 
dois pontos quaisquer da reta $r_{1}$ resultar no mesmo sinal do determinante entre $p_{2}$ e os mesmos dois pontos da reta $r_{1}[8]$.

\subsubsection{Média com peso proporcional à distância}

A simplificação do diagrama de Voronoi minimiza as distorções nas junções das imagens, mas não trata as diferenças na intensidade luminosa entre as imagens devido a mudanças na iluminação da cena, como pode ser notado na figura 4.2.

Existem diversas técnicas para suavizar as diferenças na intensidade luminosa entre as imagens, mas a maior parte delas tem um alto custo computacional. Assim, é utilizado um filtro simples para que a transição entre as imagens seja gradual, minimizando as bordas artificiais das junções, sem degradar demais a performance do sistema. Esse filtro calcula uma média com peso, de forma que o pixel de cada imagem seja multiplicado por uma função com peso que decresce em uma imagem e cresce na outra através da junção [5]. Suponha que uma imagem, $I e(i)$, está na esquerda e a outra, $I d(i)$, está na direita, e as imagens vão ser unidas na posição $i$ (expressas em uma dimensão para simplificar a notação). Seja a função $F e(i)$ uma função com peso que decresce uniformemente da esquerda para a direita e seja $F d(i)=1-F e(i)$. Assim, o mosaico $I$, gerado pela união destas imagens, é dado por

$$
I(i)=F e(i) I e(i)+F d(i) I d(i)
$$

Esse filtro é aplicado em $\mathrm{N}$ pixels da região de transição, onde $\mathrm{N}$ pode ser alterado pelo usuário caso ele deseje tornar a transição mais ou menos gradual. O tamanho de $\mathrm{N}$ utilizado como padrão no sistema desenvolvido é 20 pixels e este valor foi escolhido experimentalmente, dado que os resultados foram obtidos a partir de imagens com tamanho $320 \times 240$.

Para saber se um pixel está dentro desta região de transição, calcula-se a distância deste em relação à mediatriz. 
A melhoria obtida nas junções, após a aplicação desse filtro, pode ser visualizada na figura 4.2.c.

a)
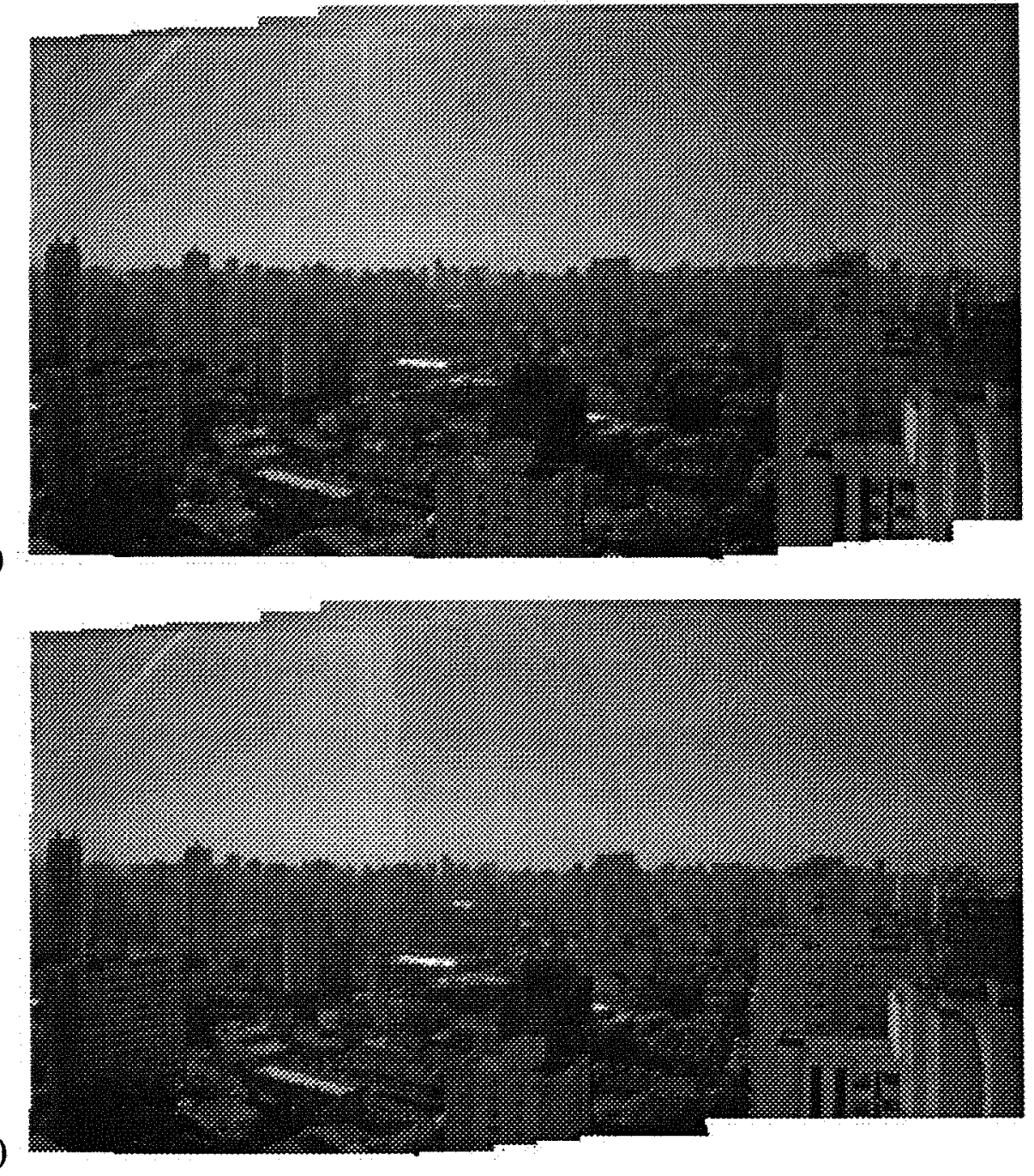
c)

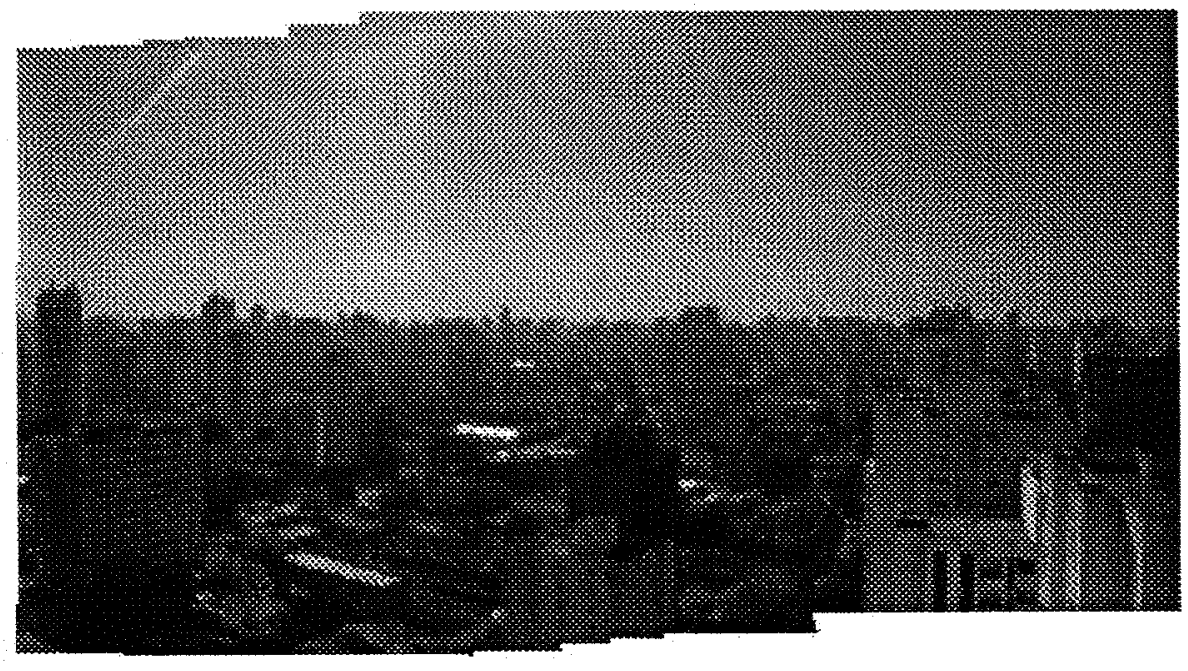

Figura 4.2: mosaicos gerado a partir de 6 imagens utilizando 3 métodos diferentes de integração:

a) Os pixels do último quadro sobrepõem o mosaico, gerando grandes descontinuidades nas bordas dos quadros correspondentes (à direita do mosaico, nos prédios que estão mais próximos), devido principalmente a distorções da lente;

b) Utiliza-se um filtro onde são escolhidos os pixels de cada imagem que estão mais próximos do centro (diagrama de Voronoi). Apesar de ter minimizado as distorções nas junções das imagens, ainda existem bordas artificiais nas junções (regiões delimitadas pela mediatriz entre os centros das imagens), devido a diferenças na intensidade luminosa;

c) Utiliza-se um filtro para que a transição entre as imagens seja gradual, minimizando as bordas artificiais das junções.

\subsection{Descrição do sistema}

O diagrama de blocos do algoritmo de alinhamento entre quadros consecutivos está representado na figura 4.3 .

A pirâmide Gaussiana da imagem de referência (quadro anterior - $\mathrm{G}_{-1}$ ) e da imagem de inspeção (quadro atual - G) é construída para ser utilizada no processo de rastreamento e estimação de movimento. A pirâmide Laplaciana $\left(\mathrm{L}_{\mathrm{H}}\right)$ é construída a partir da pirâmide Gaussiana.

$\mathrm{O}$ módulo de deteç̧ão de características utiliza $\mathrm{L}_{\mathbf{4}}{ }^{0}$ para extrair as características que serão utilizadas no rastreamento entre as pirâmides Gaussianas. O rastreamento é feito 
utilizando o algoritmo descrito na seção 2.5. Esse rastreamento retorna os deslocamentos das características na resolução mais alta da pirâmide, na qual é então utilizada para a estimação do movimento. Uma vez que a estimação do movimento foi obtida, o módulo de compensação de movimento calcula o movimento total da câmera combinando todas as estimações entre quadros no decorrer do tempo (a partir do quadro de inicial f). $\mathrm{O}$ movimento total é utilizado para alinhar o quadro atual $f$, em relação ao quadro inicial, e o resultado obtido após a aplicação dos filtros de integração descritos na seção 4.2 é desenhado na tela, gerando-se o mosaico.

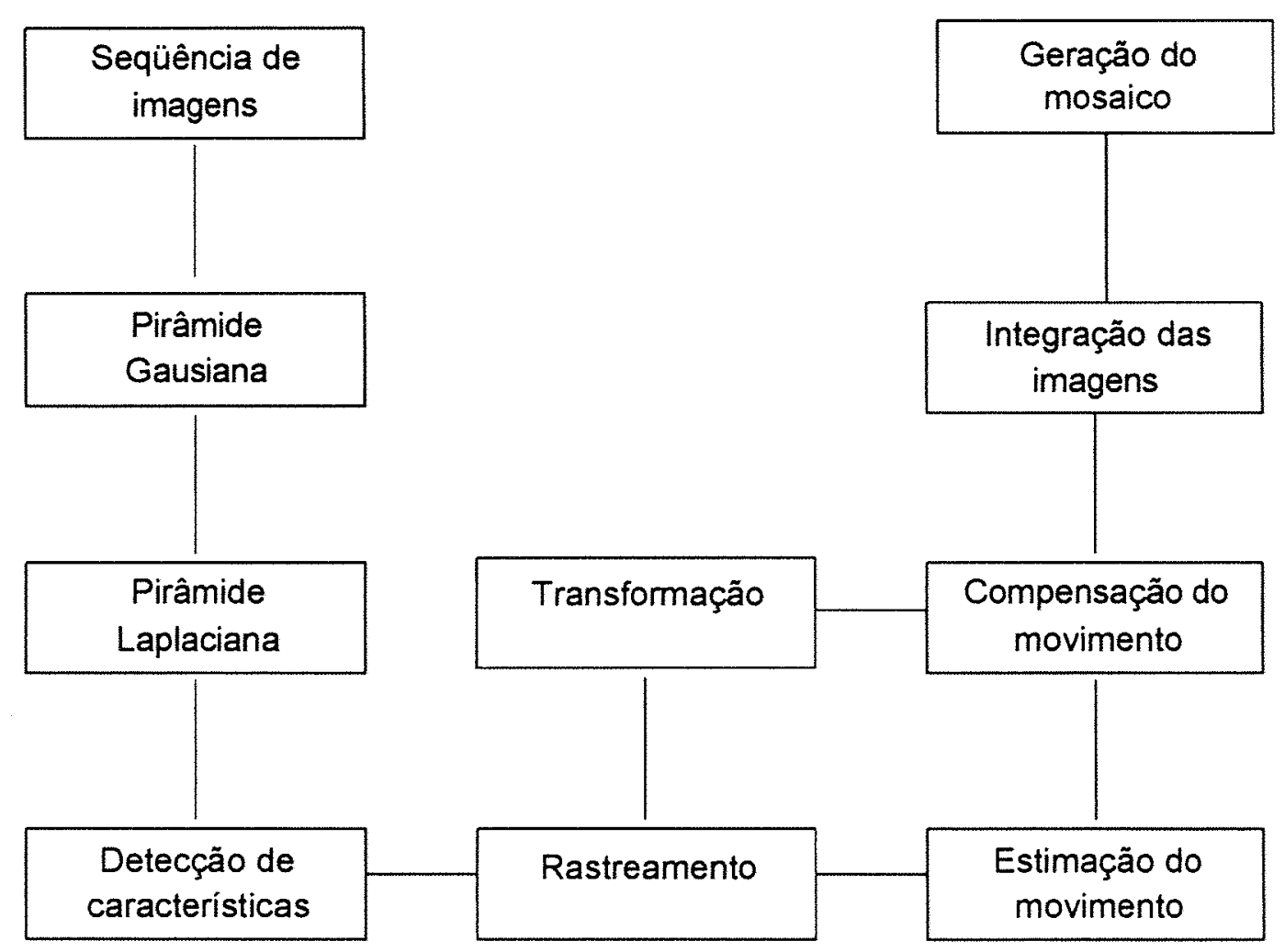

Figura 4.3: diagrama de blocos do algoritmo de alinhamento.

Como as características são rastreadas entre quadros consecutivos, elas não precisam ser extraidas em todos os quadros. $\mathrm{O}$ algoritmo de extração de características é aplicado para quadros alternados, ou seja, para um quadro sim, um quadro não, em vez de para todos os quadros. Suponha que o sistema utiliza o quadro f para extrair as características. Tal conjunto de características é utilizado para rastrear as características anteriores (entre 
$f_{f}$ e $f_{t-1}$ ). Quando $f_{+1}$ é obtido, o mesmo conjunto pode ser utilizado para rastrear as características posteriores (entre of e $f_{+1}$ ). Finalmente, quando $f_{t+1}$ é obtido, novas características devem ser extraídas e o processo continua para rastrear as características anteriores. Essa estratégia é muito simples de ser implementada e requer apenas uma estrutura de controle um pouco mais complexa. 


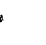




\section{Resultados}

$\mathrm{Na}$ figura 5.1.g, pode-se observar o mosaico obtido a partir de uma seqüência de 29 imagens, nas quais a câmera foi movida, em sua maioria, da esquerda para a direita, com pequenas rotações ao redor do eixo óptico.

Como a cena é composta somente por objetos muito distantes da câmera (silhueta dos prédios do bairro Vila Olímpia, em São Paulo), não existem distorções devido a paralaxe 3D. Assim, o sistema desenvolvido é capaz de gerar mosaicos com boa qualidade a partir de cenas com essas características.

Além disso, a diferença na tonalidade das imagens, principalmente na parte direita do mosaico, onde o sol estava mais próximo (pode-se observar os raios de sol na figura 5.1.f), foi suavizada.

a)

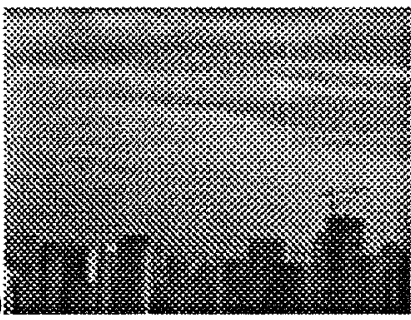

b)

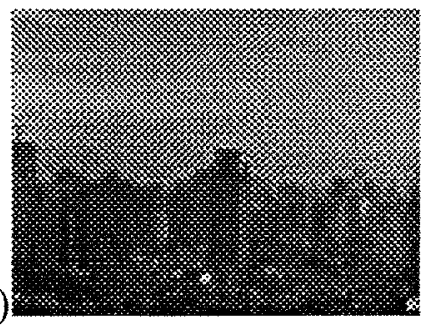

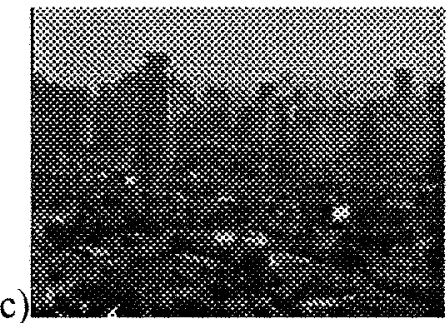



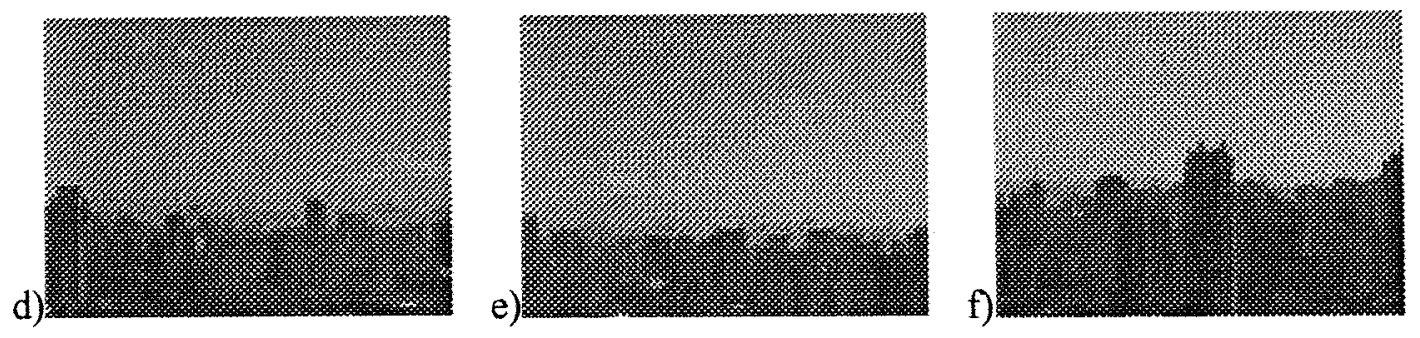

g)

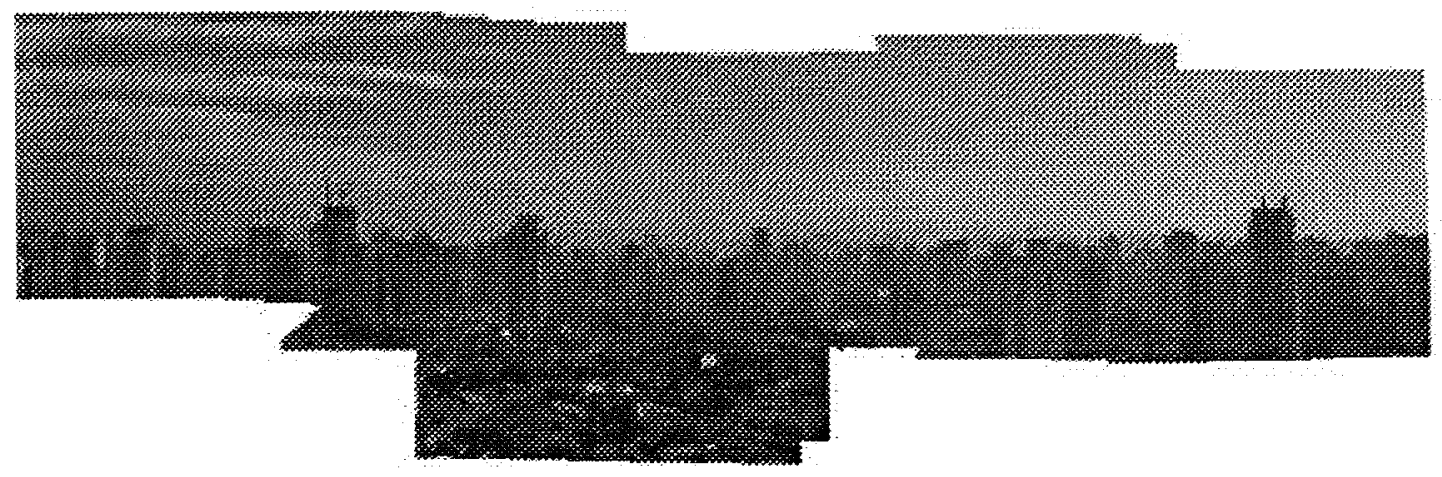

Figura 5.1: exemplo de mosaico gerado a partir de uma seqüência de imagens da silhueta dos prédios do bairro Vila Olímpia, em São Paulo. a - f) Quadros 1, 8, 12,16,21, 29 da seqüencia de imagens, respectivamente.

g) Mosaico gerado a partir de uma seqüência de 29 imagens, em que a câmera foi movida, em sua maioria, da esquerda para a direita, com pequenas rotações ao redor do eixo óptico e a maior parte dos objetos estão distantes da câmera.

A figura 5.3 representa o mosaico gerado a partir de 16 imagens que foram obtidas a partir de uma seqüência de vídeo. A figura 5.2 mostra os quadros $1,4,8,12,14$ e 16 dessa seqüência de imagens. Como esta seqüência de imagens foi obtida a partir de um vídeo, nota-se que não existe tanta variação na intensidade luminosa entre os quadros. Entretanto, nesta seqüência, os objetos estão mais próximos da câmera e existe uma pessoa que se movimenta um pouco no decorrer do vídeo.

Analisando as imagens de origem (figura 5.2) e o mosaico gerado (figura 5.3), verifica-se que devido ao movimento realizado por esta pessoa durante a seqüência de imagens, ele fica um pouco distorcido no mosaico gerado. 
Além disso, o movimento realizado pela câmera é predominantemente da direita para a esquerda. Mas a câmera também se movimenta inicialmente para baixo e depois para cima. Com isso, pode-se notar que quando a câmera muda sua trajetória (começa a subir), ocorrem distorções na parte inferior do mosaico (ver figura 5.3 - na altura da coxa da pessoa presente na imagem). Analisando a figura 5.4 (mosaico onde as mediatrizes entre as imagens estão impressas), verifica-se que a seleção dos pixels conforme o diagrama de Voronoi só é realizada para a borda vertical, pois a mediatriz é calculada em relação aos centros das imagens de inspeção e referência, portanto, é normal ao movimento predominante.
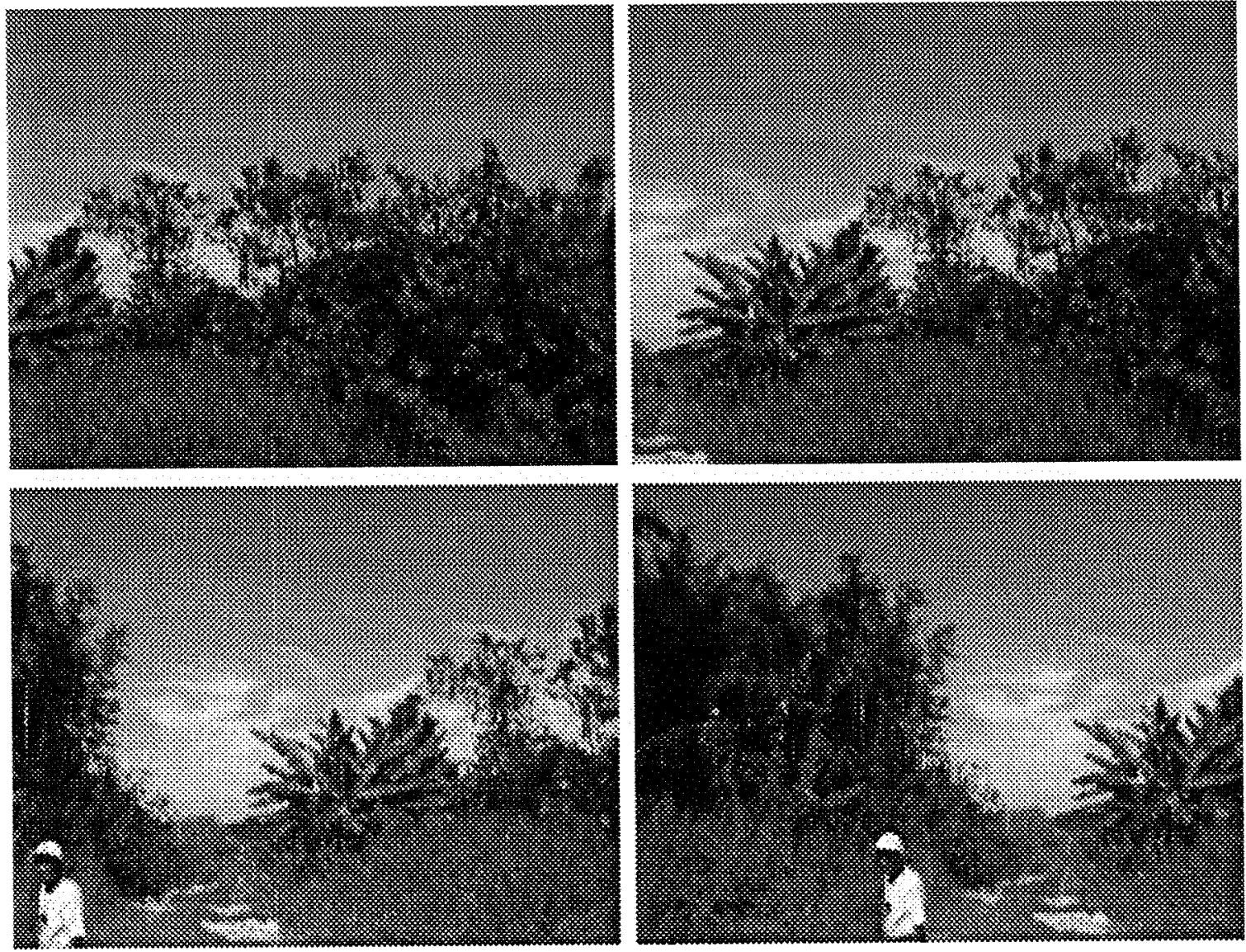

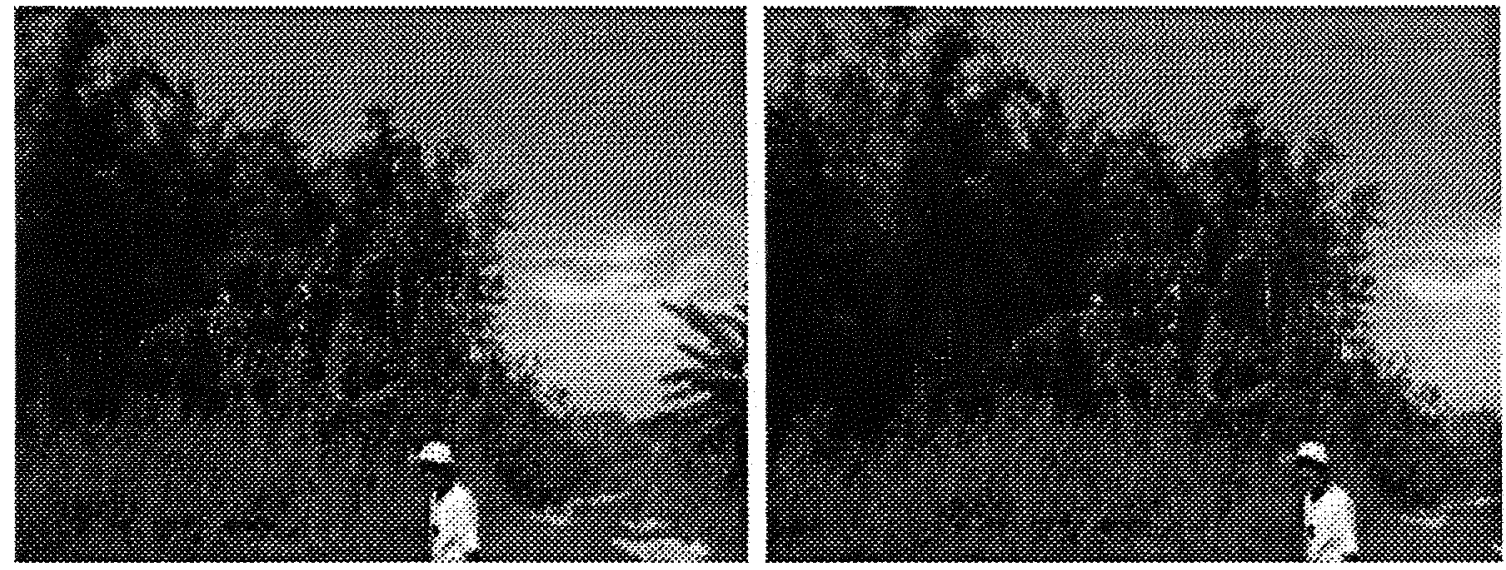

Figura 5.2: Imagens utilizadas na geração do mosaico. Correspondem aos quadros 1, 4, $8,12,14$ e 16 .

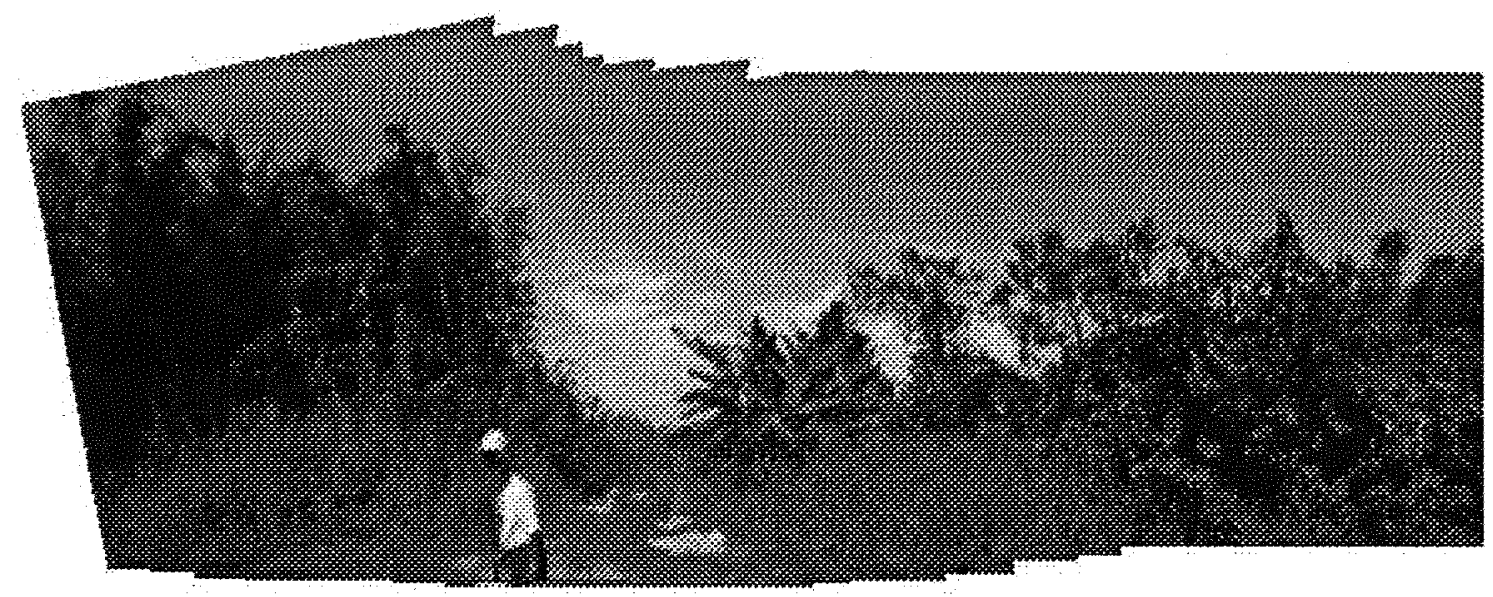

Figura 5.3: Mosaico gerado a partir uma seqüência de 16 imagens obtidas de um vídeo. 


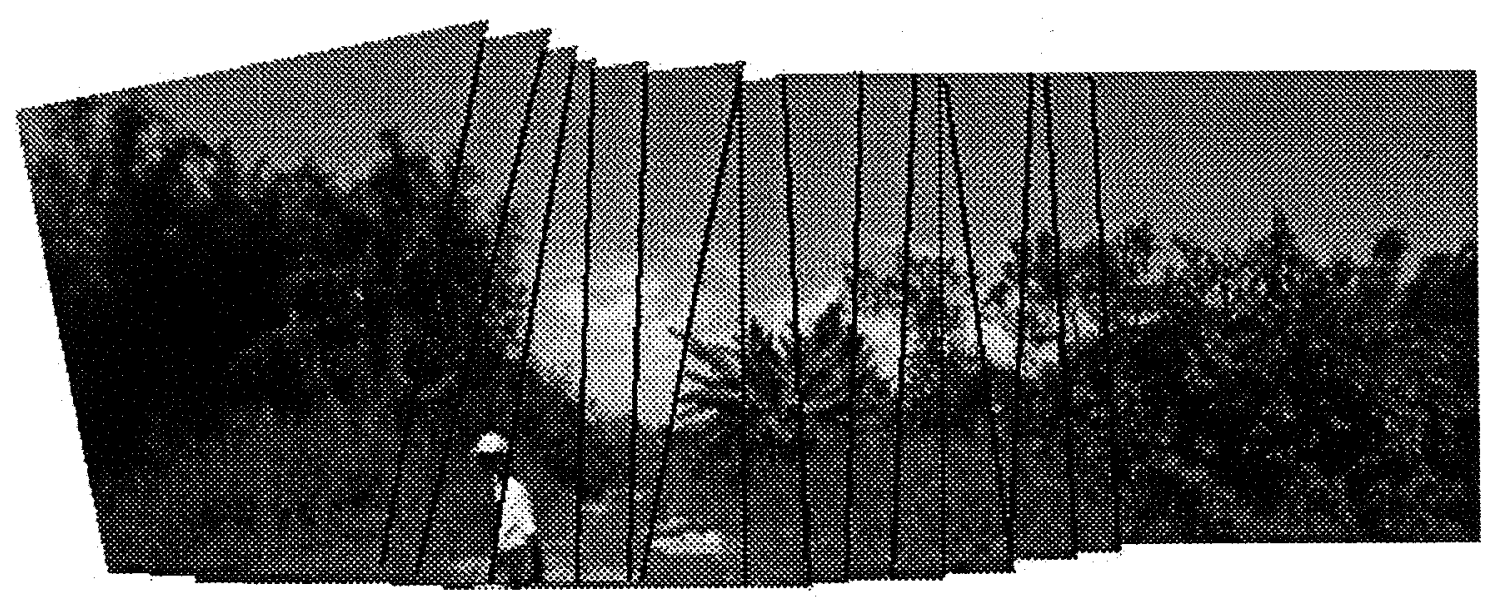

Figura 5.4:Mosaico com a mediatriz que delimita os pixels que serão pintados de cada imagem.

Para ilustrar a performance do sistema desenvolvido e o aumento do custo computacional ao aumentar-se a janela de busca ou o número de características a serem utilizadas na estimação do movimento, foram realizados os testes descritos nas tabelas 5.1 e 5.2 .

Os testes foram realizados em um notebook Dell Inspiron 5100, com processador Intel Pentium-4, 2,6 Ghz e $512 \mathrm{Mb}$ de memória, utilizando como entrada imagens com tamanho $320 \times 240$ pixels.

Conforme a tabela 5.1 o sistema desenvolvido é capaz de processar aproximadamente 10 quadros por segundo quando se tem uma janela de busca pequena, ou seja, quando o deslocamento entre os quadros sucessivos é no máximo 5 pixels. Na verdade, para deslocamentos de até 10 pixels, o tempo de processamento não muda muito. Entretanto, quando a janela de busca é grande, o processo de rastreamento da característica torna-se um dos processos mais lentos na geração do mosaico. Além disso, quando a janela de busca tem tamanho de 50 pixels, o alinhamento não é realizado com sucesso, pois o SSD da janela de correlação é calculado para tantos pontos, que o sistema não consegue mais rastrear corretamente a caracteristica.

Ao comparar a tabela $5.2 \mathrm{com}$ a tabela 5.1 , verifica-se que ao aumentar o número de características, o sistema perde muita performance. Isso ocorre, pois, é preciso estimar os parâmetros de movimento, para cada característica adicionada a imagem. 


\begin{tabular}{|l|l|l|l|l|}
\hline No. Quadros & No. Partições & s (janela de busca) & Tempo (seg.) & Alinhou? \\
\hline 10 & 4 & 5 & 0,99 & Sim \\
\hline 10 & 4 & 10 & 1,03 & Sim \\
\hline 10 & 4 & 20 & 1,11 & Sim \\
\hline 10 & 4 & 30 & 1,25 & Sim \\
\hline 10 & 4 & 40 & 1,46 & Sim \\
\hline 10 & 4 & 50 & 1,69 & Não \\
\hline
\end{tabular}

Tabela 5.1: Comparação do tempo de processamento ao aumentar a janela de busca

\begin{tabular}{|l|l|l|l|l|}
\hline No. Quadros & No. Partições & s (janela de busca) & Tempo (seg.) & Alinhou? \\
\hline 10 & 8 & 5 & 1,05 & Sim \\
\hline 10 & 8 & 10 & 1,09 & Sim \\
\hline 10 & 8 & 20 & 1,26 & Sim \\
\hline 10 & 8 & 30 & 1,56 & Sim \\
\hline 10 & 8 & 40 & 1,91 & Sim \\
\hline 10 & 8 & 50 & 2,39 & Não \\
\hline
\end{tabular}

Tabela 5.2: Comparação do tempo de processamento ao aumentar a janela de busca e o número de partições da imagem (em relação a tabela anterior). 


\section{Conclusão}

Ao longo deste trabalho foram estudados diferentes técnicas de estimação do movimento, alinhamento seqüencial e integração de imagens, com o objetivo de gerar mosaicos panorâmicos.

Analisando os principais métodos existentes, verifica-se que não existe um método que gera um "mosaico ótimo" para qualquer tipo de seqüência de imagens, na qual "mosaico ótimo" seria a visão total da cena, caso fosse possível obtê-la, tirando apenas uma fotografia desta. Isso não é possivel, pois, além de ocorrerem mudanças na cena no decorrer do tempo (objetos em movimento, mudanças de iluminação etc.), o mundo real possui uma dimensão a mais em relação às imagens utilizadas para representá-lo. Assim, dependendo das características existentes na cena, deve-se utilizar o método apropriado.

Dessa forma, o sistema desenvolvido gera mosaicos em tempo real a partir de vídeos ou sequência de imagens com as seguintes características:

- Cenas estáticas (sem objetos em movimento);

- Cenas predominantemente 2D, ou seja, em que a maior parte dos objetos situam se distantes da câmera; 
- O movimento da câmera não realiza loopings, ou seja, não deve ocorrer sobreposição entre imagens que não sejam adjacentes no tempo (quadros sucessivos);

- Existência de características facilmente identificáveis na cena, ou seja, deve-se evitar imagens com extensas áreas de brilho constante, com abundância de contornos exclusivamente horizontais ou verticais, ou contendo padrões iguais e repetitivos.

A simplificação do diagrama de Voronoi, descrita nesta dissertação, minimiza as distorções nas junções das imagens com um baixo custo computacional. Entretanto, essa técnica possui a seguinte restrição: o movimento realizado pela câmera para gerar a seqüência de imagens deve ser predominantemente em uma direção (da esquerda para direita, de baixo para cima etc.), pois se a câmera realizar um movimento em uma direção e depois voltar na direção oposta, como a seleção dos pixels só é realizada entre a imagem de inspeção e de referência, e a imagem de inspeção poderá sobrepor imagens alinhadas anteriormente no mosaico, poderão ocorrer distorções na junção da imagem de inspeção com as imagens alinhadas anteriormente. Todavia, essa restrição é facilmente satisfeita quando se tem em vista a geração de imagens panorâmicas (realizar "zig-zags" com a câmera não irá ampliar o campo de visão do mosaico).

Analisando a figura 5.4, verifica-se que para seqüências de imagens onde 0 movimento da câmera é realizado predominantemente em uma direção, a simplificação do diagrama de Voronoi produz mosaicos com boa qualidade (contendo pouca borda artificial), mesmo para cenas onde existem objetos próximos da câmera. Na verdade, nota-se que, neste caso, este método se assemelha muito com as tiras centrais da projeção manifold, onde a largura desta tira é o deslocamento existente entre duas imagens consecutivas.

A utilização da média com peso, em que a largura da mistura dos pixels das imagens (dégrade) pode ser customizada pelo usuário conforme a necessidade, diminui bastante a junção artificial devido a mudanças na intensidade luminosa entre as imagens. Entretanto, a presença de objetos em movimento próximos a junção das imagens irá gerar o efeito "fantasma", ou seja, a imagem ficará borrada nestas regiões. 
Portanto, baseado nos resultados obtidos, sugere-se as seguintes melhorias no sistema:

- Revisar o método simplificado do diagrama de Voronoi, a fim de minimizar também as distorções que ocorrem nas bordas que não são tratadas pela mediatriz atualmente;

- Criação de um filtro capaz de tratar objetos em movimento e que rode em tempo real;

- Verificar possíveis melhorias na performance do sistema atual, alterando, por exemplo, o tamanho do filtro de Gauss de $5 \times 5$ para $3 \times 3$. 


\section{.}




\section{Referências Bibliográficas}

[1] AURENHAMMER, F. Voronoi diagrams: A survey of a fundamental geometric data structure. In: ACM Computing Surveys, [S.I.], v. 23, 1991. p. 345-405.

[2] BARATA, J. C. A. Notas de aula do Curso de Física-Matemática do Instituto de Física da Universidade de São Paulo. 2004. Disponível em $<$ http://denebola.if.usp.br/ jbarata/Notas_de_aula/>. Acesso em: 25 mar. 2004.

[3] BERGEN, J. R.; ANANDAN, P.; HANNA, K.J.; HINGORANI, R. Hierarchical model-based motion estimation. In: European Conference on Computer Vision, [S.I.], 1992. p. 237-252.

[4] BERGEN, J. R.; BURT, P. J.; HINGORANI, R.; PELEG, S. A three frame algorithm for estimating two-component image motion. In: IEEE Transactions On Pattern Analysis and Machine Intelligence, [S.I.], v.14, Sept. 1992. p. 886896.

[5] BURT, P. J.; ADELSON, E. H. A Multiresolution Spline With Application to Image Mosaics. In: ACM Transation on Graphics, v. 2, n. 4, Oct. 1983. p. 217236.

[6] BURT, P. J.; ADELSON, E. H. The Laplacian Pyramid as a Compact Image Code. In: IEEE Trans. on Communications, v. 31, n. 4, Apr. 1983.

[7] CENSI, A.; FUSIELLO, A.; ROBERTO, V. Image stabilization by features tracking. In: Proceedings of the 10th International Conference on Image Analysis and Processing (ICIAP 99), Venice, Italy, 27-29 Sept. 1999. p. 665-667.

[8] FERREIRA, C. E. Notas de aula de Geometria Computacional (MAC - 747) do Instituto de Matemática e Estatística da Universidade de São Paulo. 1999. Disponivel em <http://www.ime.usp.br/ cef/geocomp/>. Acesso em: 17 abr. 2004.

[9] GARCIA, R.; BATLLE, J.; CUFI, X.; AMAT, J. Positioning an Underwater Vehicle through Image Mosaicking. In: IEEE International Conference on 
Robotics and Automation (ICRA), Seoul, Republic of Korea, v. 3, 2001. p. 27792784

[10] GONZÁLEZ, M. G.; HOLIFIELD, P.; VARLEY, M. Improved Mosaic Construction by Accumulated Alignment Error Distribution. In: Proceeding of the British Machine Vision Conference, [S.I.], v. 2, 1998. p. 377-387.

[11] GRACIAS, N.; SANTOS-VICTOR, J. Underwater video mosaics as visual navigation maps. In: Computer Vision and Image Understanding, [S.I.], v. 79, n. 1, July 2000. p. 66-91.

[12] HANNA, K. Direct multi-resolution estimation of ego-motion and structure from motion. In: IEEE Workshop on Visual Motion, Princeton, NJ, Oct. 1991. p. 156162.

[13] HORN, B. K. P.; SCHUNCK, B. G. Determining optical flow. In: Artificial Intelligence, v. 17, 1981. p. 185-203.

[14] HSU, S.; SAWHNEY, H. S.; KUMAR, R. Automated mosaics via topology inference. In: IEEE Computer Graphics and Applications, [S.I.], v. 22, n.2, Mar.Apr. 2002. p. 44-54.

[15] INTILLE, S.; BOBICK, A. Visual Tracking using closed-worlds. In: Proceedings of the 5th International Conference on Computer Vision, Cambridge, MA, 1995. p. $672-678$.

[16] IRANI, M.; ANANDAN, P. All about direct methods. In: W. Triggs, A. Zisserman, and R. Szeliski, editors, Proc. of the Int. Workshop on Vision Algorthims, [S.I.], 1999. p. 267-277.

[17] IRANI, M; ANANDAN, P. Video indexing based on mosaic representation. In: Proc. of IEEE, PAMI. May 1998. p. 905-921.

[18] IRANI, M.; ANANDAN, P.; BERGEN, J.; KUMAR, R.; HSU, S. Efficient Representations of Video Sequences and their Applications. In: Signal Processing: Image Communication, [S.I.]. 1996. p. 327-351.

[19] IRANI, M.; PELEG, S. Improving Resolution by Image Registration. In: CVGIP: Graphical Models and Image Processing, v. 53, 1991. p. 231-239. 
[20] IRANI, M.; ROUSSO, B.; PELEG, P. Recovery of ego-motion using region alignment. In: IEEE Trans. on Pattern Analysis and Machine Intelligence, [S.I.], v. 19, n. 3, Mar. 1997. p. 268-272.

[21] KANG, E.Y; COHEN, I.; MEDIONI, G. A Graph-Based Global Registration for $2 D$ Mosaics. In: Proc. Int'l Conf. Pattern Recognition (ICPR 00), Los Alamitos, California: IEEE CS Press, v. 1, 2000. p. 257-260.

[22] KOENEN, R.; PEREIRA, F.; CHIARIGLIONE, L. MPEG-4: Context and objectives. In: Signal Processing: Image Communications, v. 9, n. 4, 1997. p. 295-304.

[23] LEVIN, A.; ZOMET, A.; PELEG, S.; WEISS, Y. Seamless Image Stitching in the Gradient Domain. Prague. Submitted to ECCV '04, May, 2004.

[24] MANN, S.; PICARD, R. W. Virtual Bellows: Constructing High Quality Stills from Video. In: First IEEE International Conference on Image Processing (ICIP'94), v. 1, Austin, Texas, Nov. 1994. p. 363-367.

[25] MANN, S.; PICARD, R. W. Virtual Orbits of Projective Group: A simple approach to featureless estimation of parameters. In: MTT Media Lab; Cambridge, Oct. 1996.

[26] MARKS, R. L; ROCK, S. M.; LEE, M. J. Realtime video mosaicking of the Ocean floor. In: IEEE Journal of Oceanic Engineering, v. 20, n. 3, 1995. p. 229 241.

[27] MARR, D. Vision. New York: W.H. Freeman \& Co, 1982.

[28] MORIMOTO, C. H. Electronic Digital Image Stabilization: Design and Evaluation, with applications. Tech. Report: Center for Automation Research, University of Maryland, College Park, Dec. 1997.

[29] MORIMOTO, C. H.; CHELLAPPA, R. Fast 3D stabilization and mosaic construction. In: Proc. IEEE Conference on Computer Vision and Pattern Recognition, San Juan, PR, June 1997. p. 660-665.

[30] MOSAICO. In: Dicionário eletrônico Houaiss da língua portuguesa. Versão 1.0, Dezembro de 2001. 
[31] NAYAR, S. K. Catadioptric Omnidirectional Camera. In: Proceeding of IEEE Conference on Computer Vision and Pattern Recognition (CVPR), Peurto Rico, June 1997.

[32] ODONE, F.; FUSIELLO, A.; TRUCCO, E. Layered Representation of a Video Shot with Mosaicing. In: Pattern Analysis and Applications, [S.I.], v. 5, n. 3, 2002. p. 296-305.

[33] ODONE, F.; FUSIELlO, A.; TRUCCO, E. Robust Motion Segmentation for Content-based Video Coding. In: 6th conference on Content-based Multimedia Information Access, College de France, Paris, 2000. p. 594-601.

[34] O'ROURKE, J. Computational Geometry in C 2. ed. Cambridge, England: Cambridge University Press, Sept. 1998.

[35] PELEG, S. Elimination of seams from photomosaics. In: Proceedings of the Conference on Pattern Recognition and Image Processing, Dallas, Tex., Aug. 3-5 1981. p. $426-429$.

[36] PELEG, S.; HERMAN, J. Panoramic Mosaics by Manifold Projection. In: CVPR'97, June 1997. p. 338-343.

[37] PELEG, S.; HERMAN, J. Panoramic Mosaics with VideoBrush. In: DARPA Image Understanding Workshop, [S.I.], May 1997. p. 261-264.

[38] PERI, V. N.; NAYAR, S. K. Generation of Perspective and Panoramic Video from Amnidirectional Video. In: Proceeding of DARPA Image Understanding Workshop, New Orleans, May 1997.

[39] PRESS, W. H.; FLANNERY, B. P.; TEUKOLSKY, S. A.; VETTERLING, W. T. Numerical Recipes in C: The Art of Scientific Computing. 2. ed. Cambrigde University Press, 1992.

[40] ROUSSO, B.; PELEG, S.; FINCI, I. Mosaicing with Generalized Strips. In: DARPA Image Understanding Workshop, May 1997. p. 255-260.

[41] ROUSSO, B.; PELEG, S.; FINCI, I.; RAV-ACHA, A. Universal mosaicing using pipe projection. In: International Conference on Computer Vision, Jan. 1998. p. 945-952. 
[42] ROWE, P.; KELLY, A. Map Construction for Mosaic-Based Vehicle Position Estimation. In: International Conference on Intelligent Autonomous Systems (IAS6), [S.I.], July, 2000.

[43] SCHECHNER, Y. Y.; NAYAR, S. K. Generalized Mosaicking: High Dynamic Range in a Wide Field of View. In: International Journal of Computer Vision, v. 53, n. 3, July 2003.

[44] SEO, Y.; CHOI, S.; KIM, H.; KI-SANG, H. Where Are the Ball and Players?: Soccer Game Analysis with Color Based Tracking and Image Mosaick. In: ICIAP, 1997, p. 196-203.

[45] SHI, J.; TOMASI, C. Good features to track. In: IEEE Computer Society Conference on Computer Vision and Pattern Recognition (CVPR'94), IEEE Computer Society, Seattle, Washington, June 1994. p. 593-600.

[46] SHUM, H.-Y.; SZELISKI, R. Construction and refinement of panoramic mosaics with global and local alignment. Submitted for review, Apr. 1997.

[47] SMOLIC, A. Robust Generation of $360^{\circ}$ Panoramic Views from Consumer Video Sequences. In: Proc. VIPromCom2002, IEEE International Symposium on Video/Image Processing and Multimedia Communications, Zadar, Croatia, June 2002.

[48] SZELISKI, R. Video Mosaics for Virtual Environments. In: IEEE Workshop on Applications of Computer Vision. [S.I.]. 1994, p. 44-53.

[49] UNNIKRISHNAN, R. Globally Consistent Mosaicking for Autonomous Visual Navigation. master's thesis, tech. report CMU-RI-TR-02-22, Robotics Institute, Carnegie Mellon University, Sept. 2002

[50] WANG, J. Y. A.; ADELSON, E. H. Representing moving images with layers. In: IEEE Transactions on Pattern Analysis and Machine Intelligence, [S.I.], v. 3, n. 5, Sept. 1994. p. 625-638.

[51] WATT, A. 3D Computer Graphics. Harlow: Addison-Wesley, 2. ed., 1993. p. 210.

[52] WOLF, P. R. Elements of Photogrammetry. New York: McGraw-Hill, 1983. 
[53] YOON, H.; BAE, Y.; YANG Y. A Soccer Image Sequence Mosaicking and Analysis Method Using Line and Advertisement Board Detection. In: ETRI Journal, v. 24, n. 6, Dec. 2002. p. 443-454.

[54] YOW, D.; YEO, B. L.; YEUNG, M.; LIU, G. Analysis and Presentation of Soccer Highlights from Digüal Video. In: Proc. Asian Conference on Computer Vision, 1995.

[55] ZHENG, Q; CHELLAPPA, R. A computational vision approach to image registration. In: IEEE Trans. Image Processing, v.2, 1993. p. 311-326.

[56] ZOGHLAMI, I.; FAUGERAS, O; DERICHE, R. Using geometric corners to build a $2 D$ mosaic from a set of images. In: Proceedings of the IEEE Conference on Computer Vision and Pattern Recognition, [S.I.], 1997. p. 420-425.

[57] ZOGHLAMI, I.; FAUGERAS, O.; DERICHE, R. Using geometric corners to build a $2 d$ mosaic from a set of images. In: Proc. Computer Vision and Pattern Recognition, San Juan, PR, IEEE Computer Society Press, June 1997. p. 420425 .

[58] ZOMET, A.; PELEG, S. Applying Super-Resolution to Panoramic Mosaics. In: IEEE Workshop on Applications of Computer Vision, Prin ceton, Oct. 1998. p. 286-287. 